\title{
Impact of Stimulation Treatments on Production Performance of Horizontal Wells in the Marcellus Shale
}

Kimberly L. Larch

West Virginia University

Follow this and additional works at: https://researchrepository.wvu.edu/etd

\section{Recommended Citation}

Larch, Kimberly L., "Impact of Stimulation Treatments on Production Performance of Horizontal Wells in the Marcellus Shale" (2012). Graduate Theses, Dissertations, and Problem Reports. 3361.

https://researchrepository.wvu.edu/etd/3361

This Thesis is protected by copyright and/or related rights. It has been brought to you by the The Research Repository @ WVU with permission from the rights-holder(s). You are free to use this Thesis in any way that is permitted by the copyright and related rights legislation that applies to your use. For other uses you must obtain permission from the rights-holder(s) directly, unless additional rights are indicated by a Creative Commons license in the record and/ or on the work itself. This Thesis has been accepted for inclusion in WVU Graduate Theses, Dissertations, and Problem Reports collection by an authorized administrator of The Research Repository @ WVU. For more information, please contact researchrepository@mail.wvu.edu. 


\title{
Impact of Stimulation Treatments on Production Performance \\ of Horizontal Wells in the Marcellus Shale
}

\author{
Kimberly L. Larch \\ Thesis submitted to the \\ Benjamin M. Statler College of Engineering and Mineral Resources \\ At West Virginia University \\ In partial fulfillment of the requirements \\ For the degree of \\ Master of Science \\ In \\ Petroleum and Natural Gas Engineering
}

Khashayar Aminian, Ph.D., Chair

Samuel Ameri, M.S.

Diane M. Corwin

Department of Petroleum and Natural Gas Engineering

\author{
Morgantown, West Virginia
}

2012

Keywords: Marcellus Shale; Stimulation; Hydraulic Fracturing

Copyright 2012 Kimberly L. Larch 


\section{ABSTRACT \\ Impact of Stimulation Treatments \\ on Production Performance \\ of Horizontal Wells in the Marcellus Shale}

\section{Kimberly L. Larch}

The interest in exploitation of ultra-low permeability formations, such as the Marcellus Shale, has increased in the recent years. Shale formations require massive stimulation treatments to achieve economic production. The recent advances in horizontal drilling and multistage hydraulic fracturing have proved successful in achieving commercial production. However, the parameters that directly affect lifetime production of the wells have not been well established.

The primary objective of this study is to examine the effects of basic stimulation parameters used in hydraulic fracturing of Marcellus Shale wells on production performance. Historical production data and stimulation treatment information have been collected and analyzed for a number of horizontal wells both in West Virginia and Pennsylvania. A commercial reservoir simulator which utilizes a dual porosity model and accounts for adsorbed gas was utilized for history matching and predicting the long term production performance. The impact of the stimulation parameters including the number of stages, stage spacing, the volume of water used, and the volume of sand used on production performance was investigated. Examination of the results revealed that stage length and stage spacing impacted the initial production of a horizontal well, but did not necessarily promote greater recovery. It was also identified that the volume of water per stage and the volume of sand per stage correlated to 10year predicted cumulative production. Increased production resulted from both larger sand and larger water volumes. 


\section{Acknowledgements}

I would like to take this opportunity to thank all of the people and organizations that have been instrumental in assisting my research and the completion of my thesis. First of all, I would like to thank the Department of Petroleum and Natural Gas Engineering in the Benjamin M. Statler College of Engineering and Mineral Resources at West Virginia University. The department has certainly increased my understanding of the petroleum and natural gas industry and has prepared me for a successful career and lifelong enjoyment of this interesting science.

Secondly, I would like to thank all members of my thesis committee for their encouragement, helpful suggestions, and guidance. Dr. Aminian, your knowledge and understanding of both modeling and reservoir engineering is second to none, and I have learned so much from working side by side with you. Professor Sam, your kind encouragement and support of my work has been foundational for allowing me to complete my work. Diane, thank you so much for allowing me to discuss my results and data with you and for providing your viewpoint directly from the industry.

Next, Northeast Natural Energy deserves much credit for supporting my thesis in the forms of data and maps. The resources that Northeast provided essentially made my study possible. Without assistance from Northeast, my research would have been much simpler and would have not been characteristic of such a large area. I want to specifically thank John Adams with assisting me in gathering production and completions data. Also, I want to thank the members of the geology department, BJ Carney, Donny Wehrle, and Bill Queen, for assisting me in finding geological properties and for sharing and generating the maps used in this project. Thank you!

Lastly, I want to thank all of my family and friends who have supported me through this time. My family has supported and encouraged my education over the years, and for this I am truly thankful. I want to especially thank my husband, Andrew Ayers, for encouraging me along the way, for being intrigued with my work, and for lovingly supporting me in all that I do. 


\section{Table of Contents}

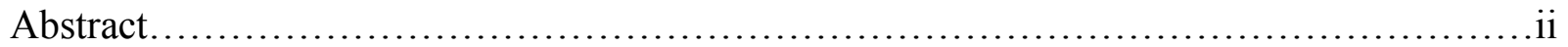

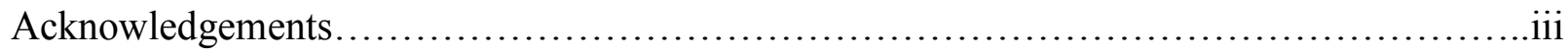

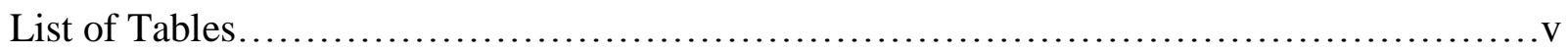

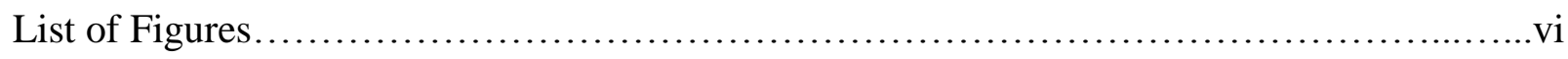

Chapter 1: Introduction .......................................................

Chapter 2: Literature Review................................................. 10

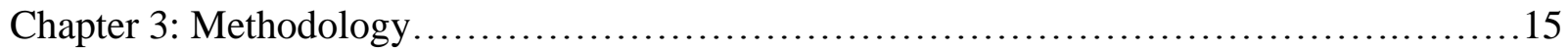

Chapter 4: Results and Discussion.............................................. 17

Chapter 5: Summary and Conclusions.............................................

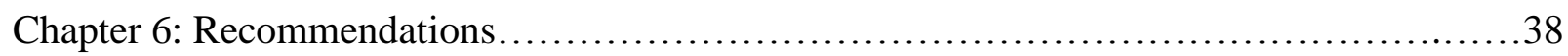

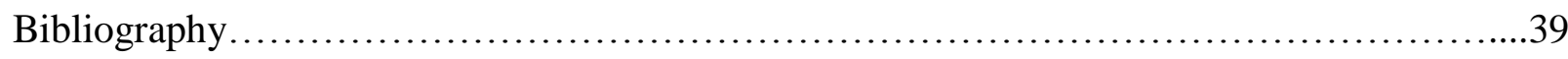

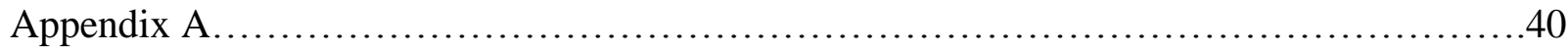

Appendix B................................................................... 46

Curriculum Vitae.................................................................. 


\section{List of Tables}

Table 4.1: Initial data set............................................................ 17

Table 4.2: Initial data set technical data averages....................................... 17

Table 4.3: Range of fracturing parameters in final study group.........................21

Table 4.4: ECLIPSE base model parameters.........................................

Table 4.5: Fracture characteristics of modeled wells..................................27

Table 4.6: Modeling cumulative results...............................................

Table 4.7: Modeling results based on number of stages................................... 31 


\section{List of Figures}

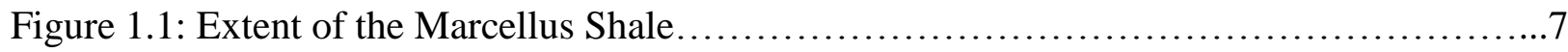

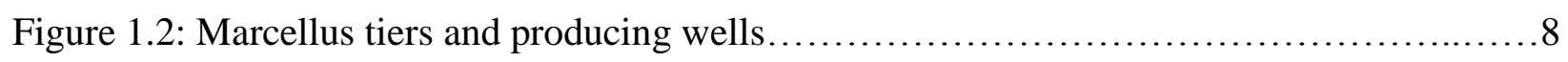

Figure 2.1: Extent of U.S. shale gas plays............................................... 10

Figure 2.2: Devonian stratigraphic column............................................11

Figure 2.3: Illustration of horizontal drilling and hydraulic fracturing........................12

Figure 2.4: Detailed illustration of hydraulic fracturing....................................13

Figure 3.1: Methodology flowchart....................................................... 16

Figure 4.1: Technical well data statistics versus date......................................... 19

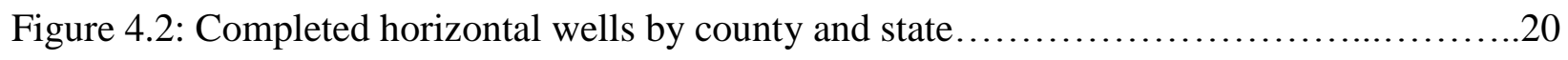

Figure 4.3: Map of Greene and Wetzel County study wells................................22

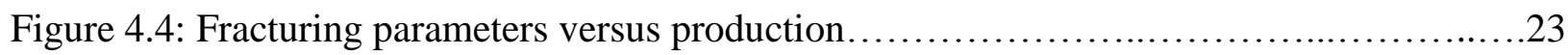

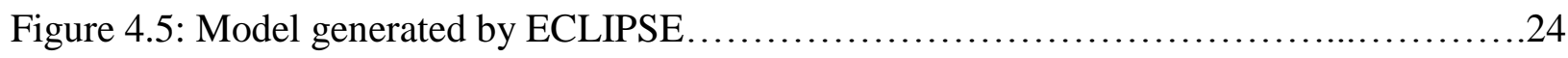

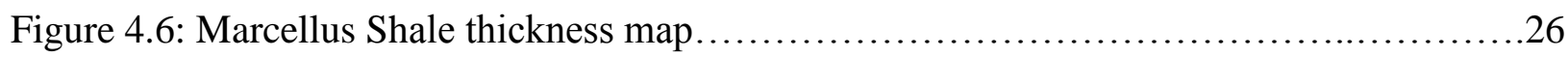

Figure 4.7. Model parameters varied during history matching ..............................28

Figure 4.8: Study well S2 daily flow rate and cumulative production curves....................29

Figure 4.9: Stage length versus cumulative predicted production............................32

Figure 4.10: kh versus 10 year predicted production...................................... 32

Figure 4.11: Production per stage versus water volume per stage............................33

Figure 4.12: Production per stage versus sand volume per stage..............................34

Figure 4.13: Production per stage versus water-sand ratio..................................... 35 


\section{Chapter 1}

\section{Introduction}

The Marcellus Shale is a significant source of natural gas located in the Appalachian Basin. This black organic shale is prolific in size-underlying sections of Pennsylvania, West Virginia, Ohio, and New York. Figure 1.1 shows the extent of the Marcellus Shale in the Appalachian Basin. Current studies estimate that 487 trillion cubic feet of recoverable reserves with 50\% probability are present in the Marcellus Shale (Engelder, 2009). This large quantity of natural gas is located very strategically in regards to geography, and will become an invaluable source of energy for industrial processes in the Northeastern areas, Eastern Seaboard, and Great Lakes region of the United States.

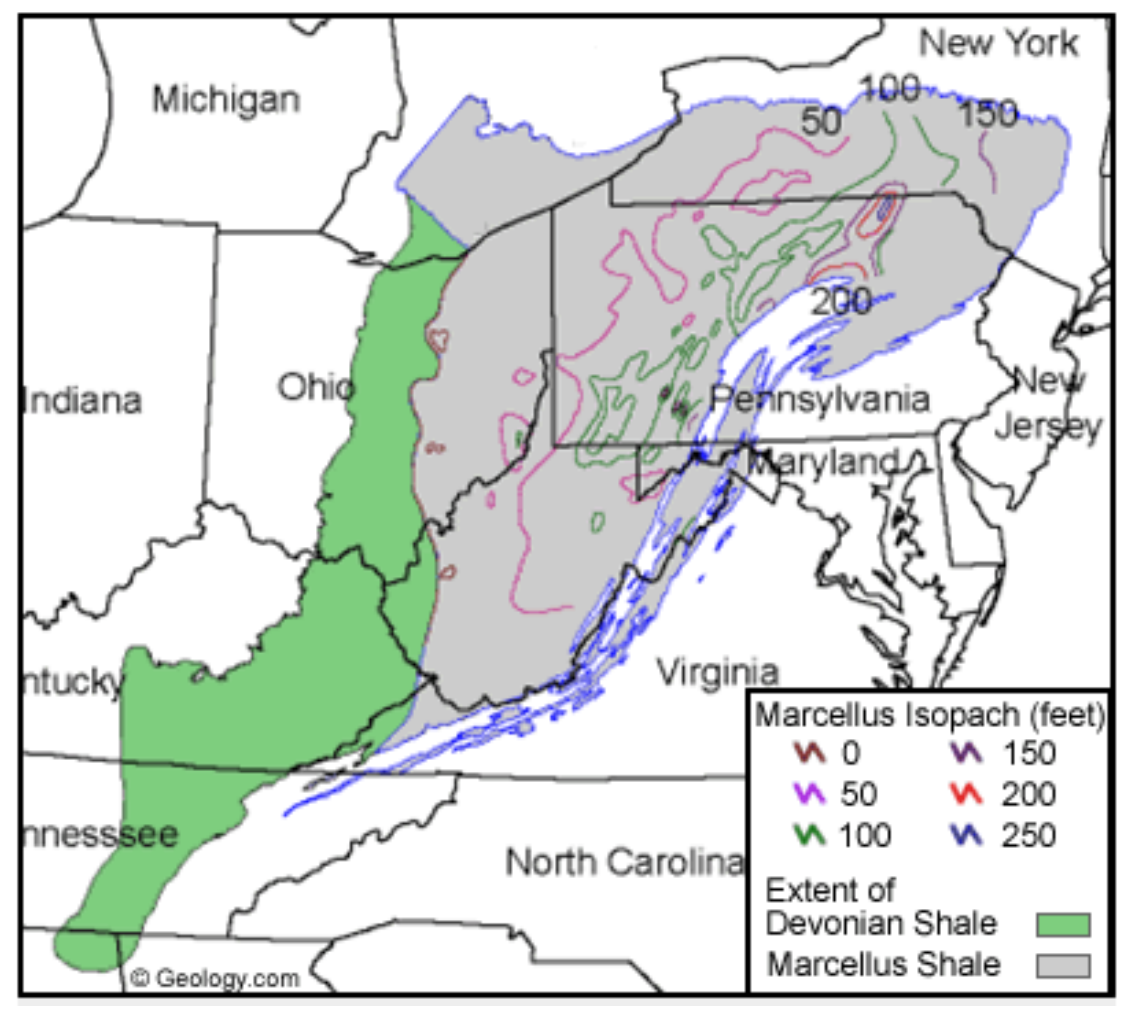

Figure 1.1: Extent of the Marcellus Shale. ("Marcellus Shale”, 2012).

Located 4,500 feet to 8,500 feet underground, the natural gas in the Marcellus Shale is accessed and produced most efficiently by using innovative horizontal drilling practices in combination with massive hydraulic fracturing stimulation treatments. These technologies allow enormous amounts of gas to be released from each individual well. Horizontal drilling makes it 
possible to contact and produce large portions of the reservoir from one surface location. The total drainage area of horizontal wells is many times larger than the area drained by traditional vertical wells in the same target zone. The well stimulation practice known as hydraulic fracturing creates micro-fissures in the rock and permits fluid flow, thus allowing natural gas and other hydrocarbons to be produced. In the Marcellus Shale, this stimulation is crucial to the production of natural gas because of the ultra-low permeability of the rock.

As of June 2011, over 3,000 Marcellus Shale wells have reportedly been drilled, as recorded by the West Virginia and Pennsylvania Departments of Environmental Protection. Thousands more have been permitted to be drilled in the future. Figure 1.2, created by Northeast Natural Energy (NNE), illustrates the location of the majority of these wells, represented by the red dots. The wells shown in the Figure were reported to be horizontal, Marcellus Shale wells producing natural gas as of December 2011. As would be expected, drilling activity has mainly

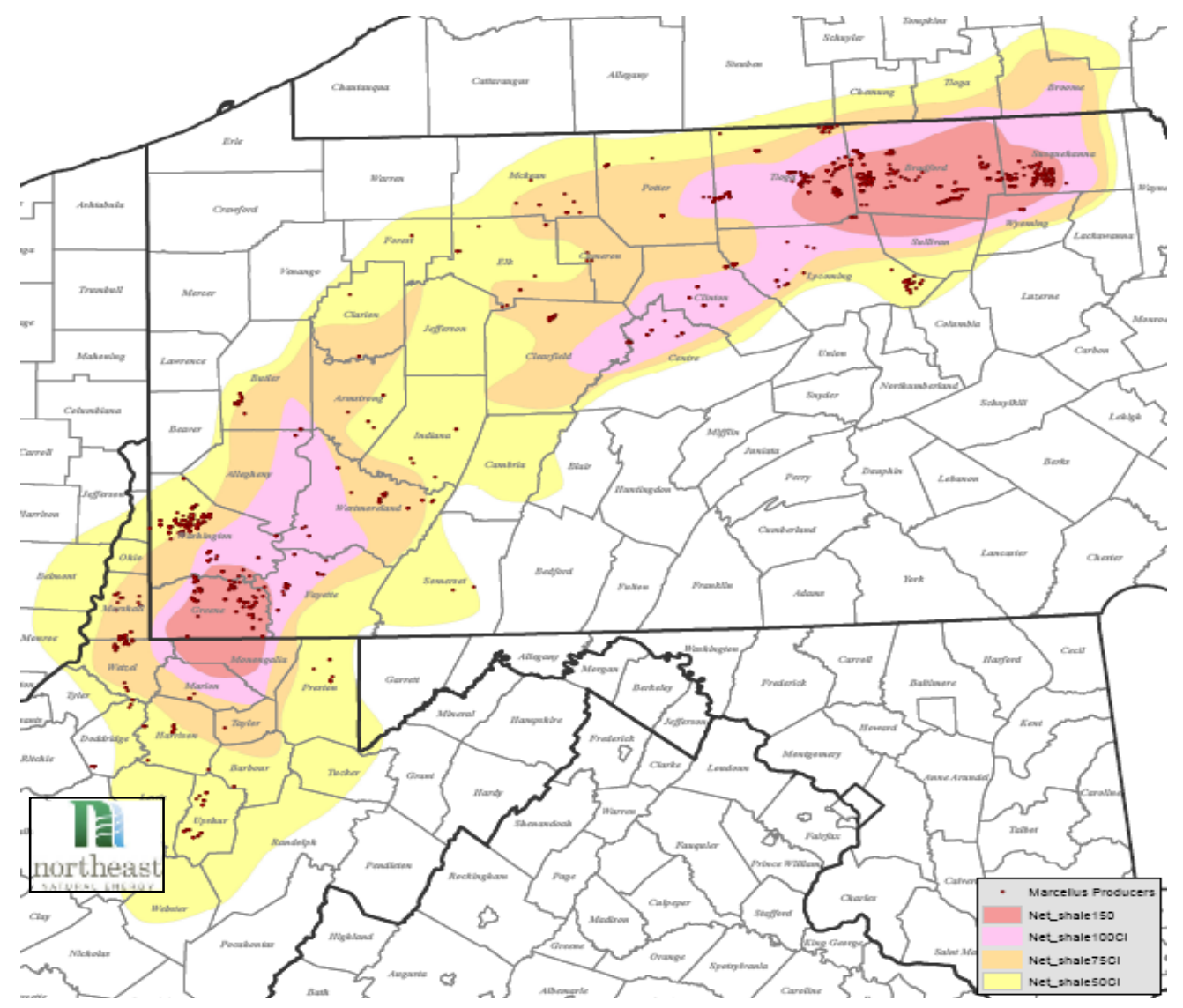

Figure 1.2: Marcellus Tiers and Producing Wells. (Courtesy of NNE). 
been concentrated around the most productive regions of the shale. As shown in Figure 1.2, these areas are located in Southwestern Pennsylvania (Greene County) and Northeastern Pennsylvania (Bradford and Susquehanna Counties).With the recent decline in natural gas prices, a significant portion of drilling activity has moved to the western portions of the shale, because wet gas has been determine to be produced by the formation there, and is a more lucrative venture. The color tiers shown in Figure 1.2 delineate areas that geologists have determined to be potentially the most productive based on electrical logs, petrophysical analysis, seismic interpretation, formation thickness, thermal maturity, and state reported production information. The light red areas designate the most productive zones, then decreasing to the pink zones, and finally the orange and yellow zones.

With this background understanding of horizontal drilling and hydraulic fracturing, this study will seek to more clearly understand the relationship of certain specific hydraulic fracturing parameters to the overall lifetime productivity of horizontal Marcellus Shale wells. 


\section{Chapter 2}

\section{Review of Literature}

\section{Section 2.1: Shale Deposits}

Shale deposits have recently been identified as an extremely significant and widespread source of energy in the form of natural gas, and occasionally oil. Shale is more widely present across the world than conventional oil and natural gas formations. These "unconventional" gas plays have recently been identified as huge sources of domestic energy for the United States. Figure 2.1 below shows the extent of shale gas play in the lower forty-eight states, and it is easily observable how significant these shales will be for the United States energy future due to the sheer size and widespread distribution of these plays.

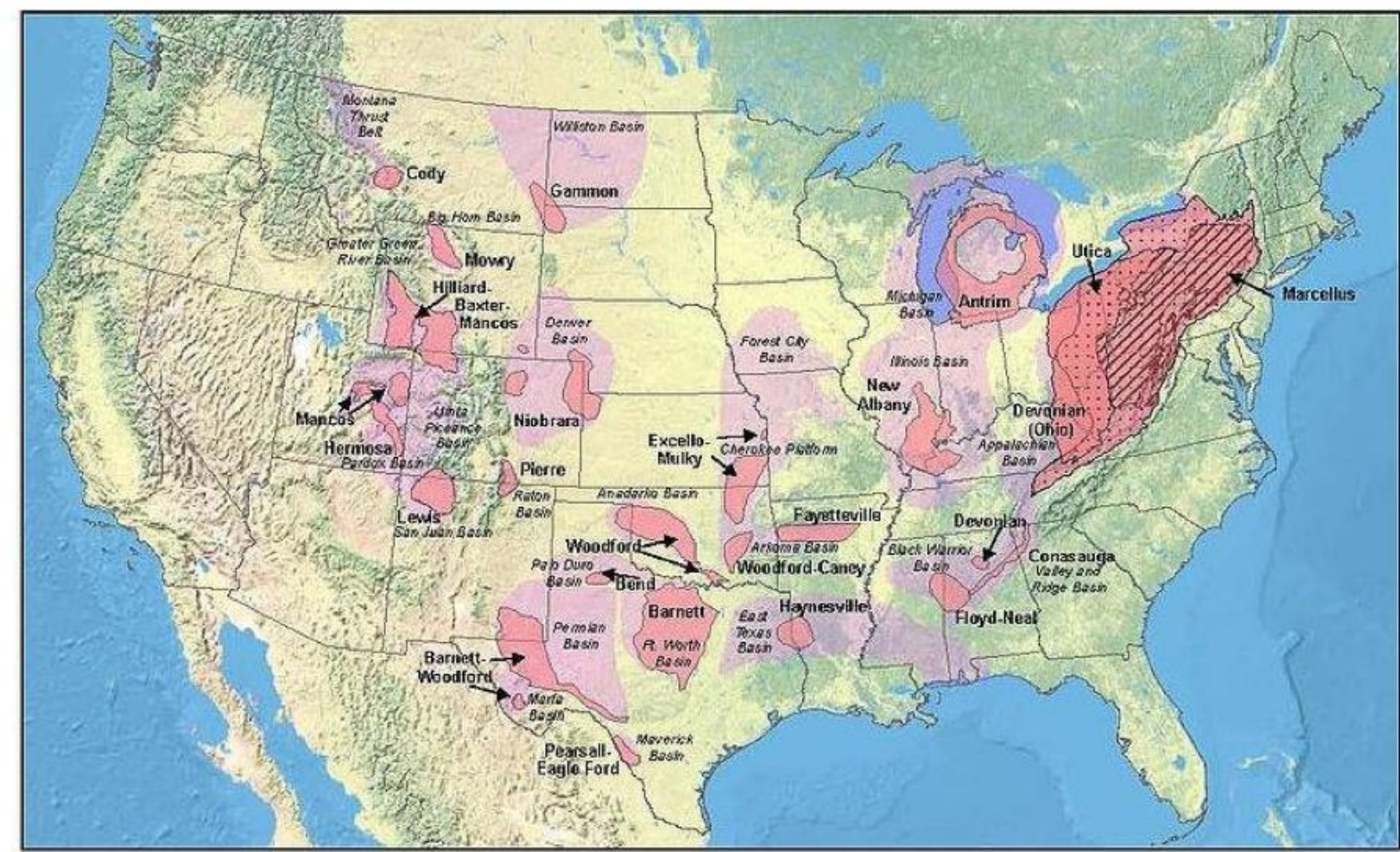

\section{United States Shale Gas Plays}
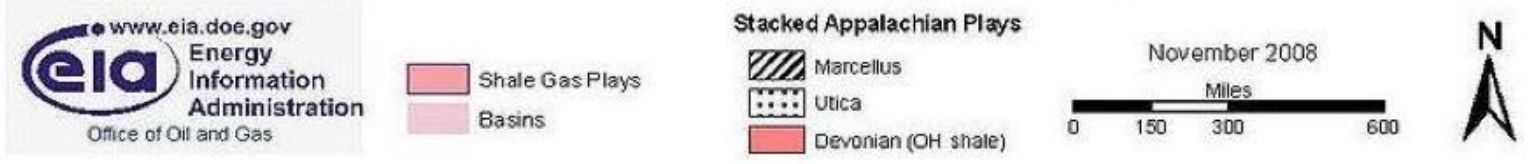

Figure 2.1: Extent of U.S. shale gas plays. (EIA, 2008) 
As mentioned in the introduction, the Marcellus Shale is a huge part of the domestic energy future involving natural gas. The Marcellus is conveniently located near very industrially active cities and heavily populated areas of the northeastern part of the United States. This location itself makes the play extremely important. Secondly, the shear size and available recoverable reserves from this formation are astounding. It has been predicted that drilling activities could be present in the shale for the next thirty years with production from these wells for the next sixty to ninety years!

\section{Section 2.2: Horizontal Drilling in the Marcellus Shale}

In terms of stratigraphy, the Marcellus Shale is located in the Middle Devonian geological group (NETL, 2010). Figure 2.2 shows the stratigraphic column in this region. Historically, operators in the Appalachian Basin have produced many of the gas sands located above and below the Marcellus Shale. The Marcellus has long been known as a very gaseous

\begin{tabular}{|c|c|c|c|}
\hline \multicolumn{2}{|c|}{ Period } & \multicolumn{2}{|c|}{ Group/Unit } \\
\hline Penn & & Pottsv & \\
\hline Miss & & Pocon & \\
\hline \multirow{14}{*}{ 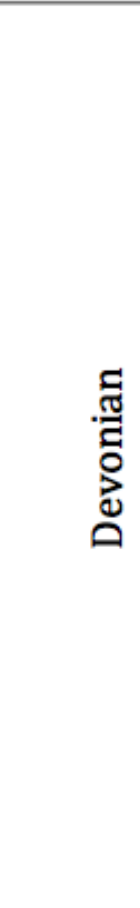 } & \multirow{6}{*}{ Upper } & \multicolumn{2}{|c|}{ Conewango } \\
\hline & & \multicolumn{2}{|c|}{ Conneaut } \\
\hline & & \multicolumn{2}{|c|}{ Canadaway } \\
\hline & & \multicolumn{2}{|c|}{ West Falls } \\
\hline & & \multicolumn{2}{|c|}{ Sonyea } \\
\hline & & \multicolumn{2}{|c|}{ Genesee } \\
\hline & \multirow{5}{*}{ Middle } & \multicolumn{2}{|c|}{ Tully } \\
\hline & & \multirow{4}{*}{ 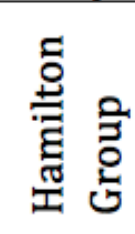 } & Moscow \\
\hline & & & Ludlowville \\
\hline & & & Skaneateles \\
\hline & & & Marcellus \\
\hline & & \multicolumn{2}{|c|}{ Onandaga } \\
\hline & \multirow{2}{*}{ Lower } & \multicolumn{2}{|c|}{ Tristates } \\
\hline & & \multicolumn{2}{|c|}{ Helderberg } \\
\hline
\end{tabular}

Figure 2.2: Devonian stratigraphic column. (NETL, 2010) 
rock and has caused drillers problems for decades. However, not until recently with the improvements and combination of horizontal drilling and hydraulic fracturing has it been possible to produce the gas from this zone in an economic manner. Horizontal drilling, as implied by the name, allows drillers to steer the drill bit and bottom hole assembly in such a manner that the wellbore actually turns horizontally. Because of this, it is now possible to access the gas-filled rock through direct contact with the wellbore for thousands of feet, in comparison to conventional vertical drilling that only contacted the formation as a function of the zone's natural thickness. Figure 2.3 illustrates these concepts of horizontal drilling in combination with hydraulic fracturing.

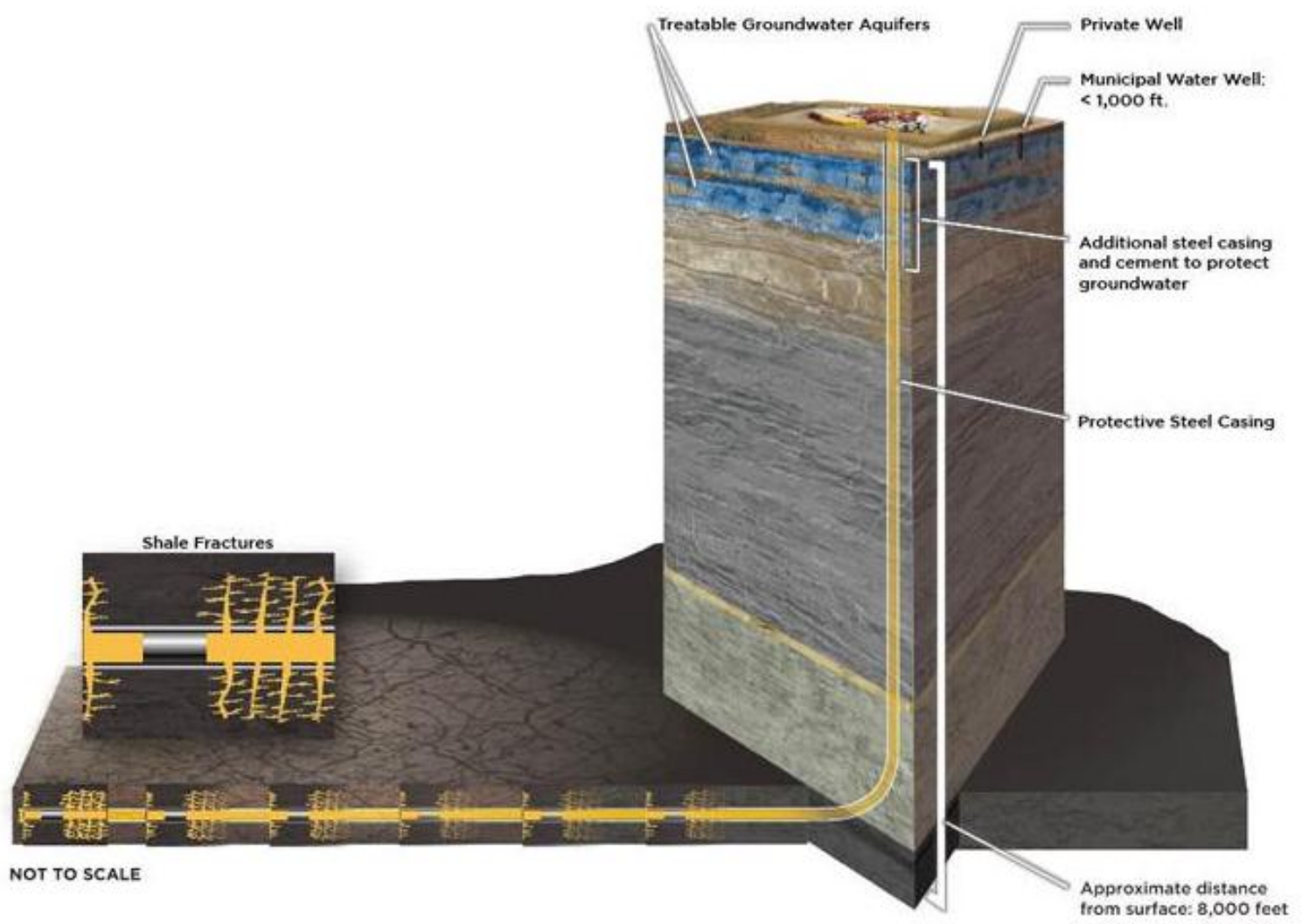

Figure 2.3: Illustration of horizontal drilling and hydraulic fracturing.

("Virginia Department of Mines," 2006)

\section{Section 2.3: Hydraulic Fracturing}

Hydraulic fracturing has many different applications and purposes. Some of the most important and pertinent to the Marcellus Shale include the following: to increase the flowrate of oil and/or natural gas from low permeability reservoirs, to connect the natural fractures in the 
formation to the wellbore, to increase the area of drainage or the amount of formation in contact with the wellbore, and to connect the full vertical extent of a reservoir to a horizontal wellbore (DOE, 2004). The stimulation practice known as hydraulic fracturing involves using intense pressures to create extremely small, but long cracks in a hydrocarbon containing rock. These fractures are achieved through pumping millions of pounds of sand, known as proppant, and thousands of gallons of water into the rock at high pressures. These pressures must overcome the in situ critical stresses that naturally occur in the rock in order to propagate the fracture out into the formation. These small cracks allow the hydrocarbons to naturally flow from the surrounding rock and into the wellbore, which is a lower pressure zone, and then successively to the surface for production and distribution. Figure 2.4 generally illustrates this process. This overall process is performed in sequential stages, as illustrated by Figure 2.3. These "stages" allow for smaller, focused areas of the rock to be fractured, and are separated by composite plugs, which isolate the previous stages from the subsequent stages.

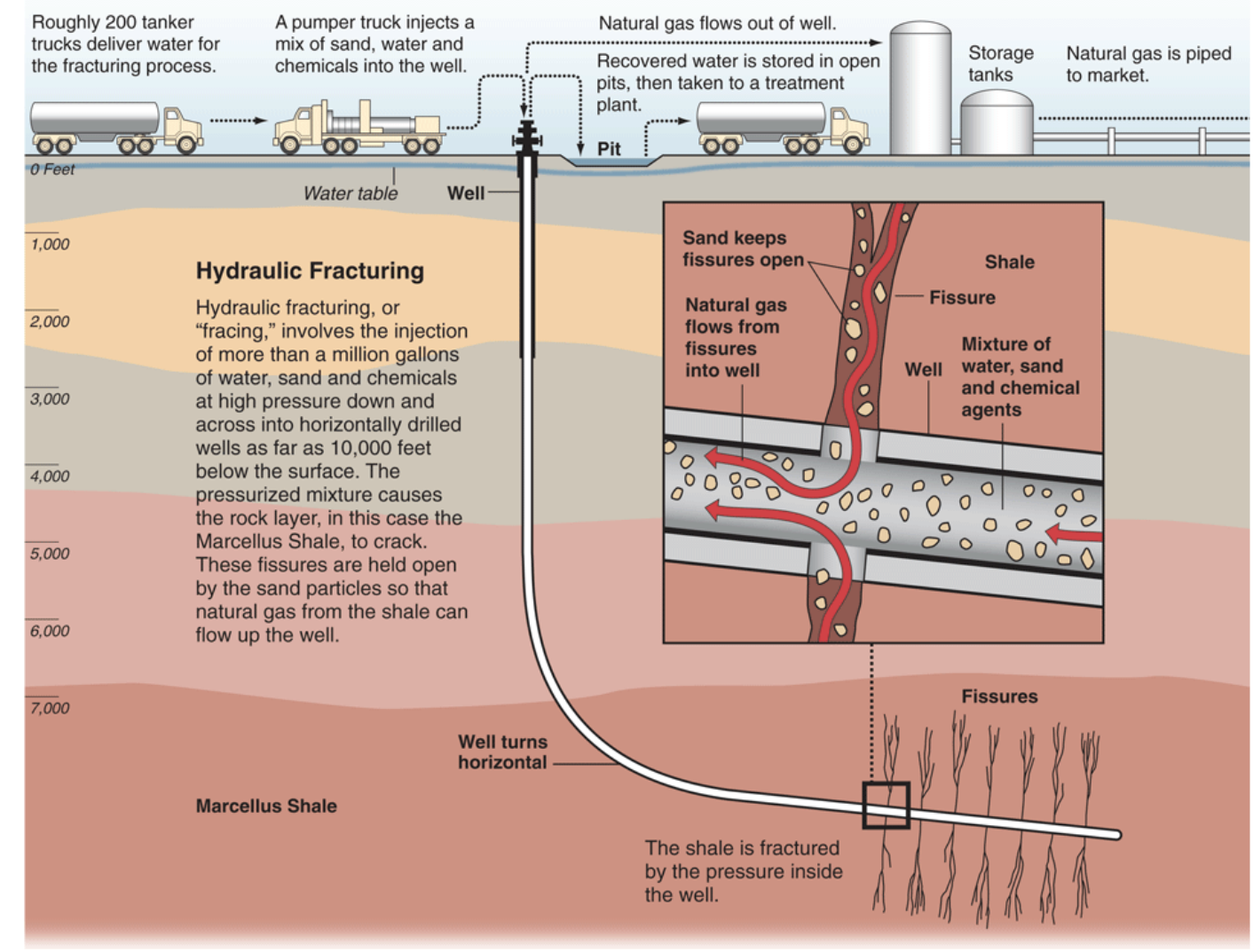

Figure 2.4: Detailed illustration of hydraulic fracturing. ("What is Hydraulic Fracturing," 2012) 


\section{Section 2.4: Simulation Modeling}

In this project, the majority of the work involving the commercial reservoir simulator, ECLIPSE, was based on a previous study performed at the West Virginia University Department of Petroleum and Natural Gas Engineering by Mr. Hossein Belyadi entitled "Production Analysis of Marcellus Shale". In his research, Belyadi developed a base model for both vertical and horizontal wells in Upshur County, West Virginia (Belyadi, 2011). This study was a great foundation for understanding the fundamental settings and model design when using ECLIPSE. The current study modifies this base model to predict the long-term production of wells located in the Marcellus Shale in a more comprehensive manner. The model incorporates many of the complex reservoir properties that are present in the Marcellus Shale. These properties include horizontal wellbore, multiple fractures, dual porosity, adsorbed gas, hydraulic fracture geometry and characteristics, and in situ rock properties. ECLIPSE is based around a template style system. All pertinent information concerning the reservoir and the stimulation are initially built into this template. The template then generates a three-dimensional model of the well and subsequently performs flow and production analysis from this model. 


\section{Chapter 3}

\section{Methodology}

The primary objective of this study was to examine the basic stimulation parameters used in hydraulic fracturing of Marcellus Shale wells and their relationship to lifetime production performance of these wells. With these recent advances in technology and the combination of horizontal drilling and hydraulic fracturing, multistage fracturing operations have proved extremely successful. However, the fracturing parameters that most directly affect the overall lifetime production of these unconventional shale wells are not well established. The optimization of these parameters could result in the increased ultimate recovery of hydrocarbons from the shale, thus increasing the net present value of each well. The parameters under evaluation in this study include the number of hydraulic fracturing stages in a horizontal well, the stage spacing or length, the volume of water used per stage, and the volume of sand injected per stage.

The objectives of this study were achieved through several different means. A flowchart for the methodology used in this research is shown in Figure 3.1.

- Historical production data was acquired from completed Marcellus Shale wells throughout the states of West Virginia and Pennsylvania. Additionally, well completion and stimulation data as reported to state agencies was gathered. Commercial reservoir modeling software was used for history matching and production forecasting. First, the necessary data was collected from the various state agencies. This data was then narrowed and a small, final set of study wells was chosen. The characteristics present in these wells were evaluated and examined. In parallel to this, a basic model was developed and refined for predictive production evaluation of horizontal shale wells. This model was then used to history match the historical production of selected study wells. This process developed a refined predictive model in four different areas of the Marcellus Shale. The results of the history matching were then analyzed and conclusions were drawn for each fracture parameter examined. 


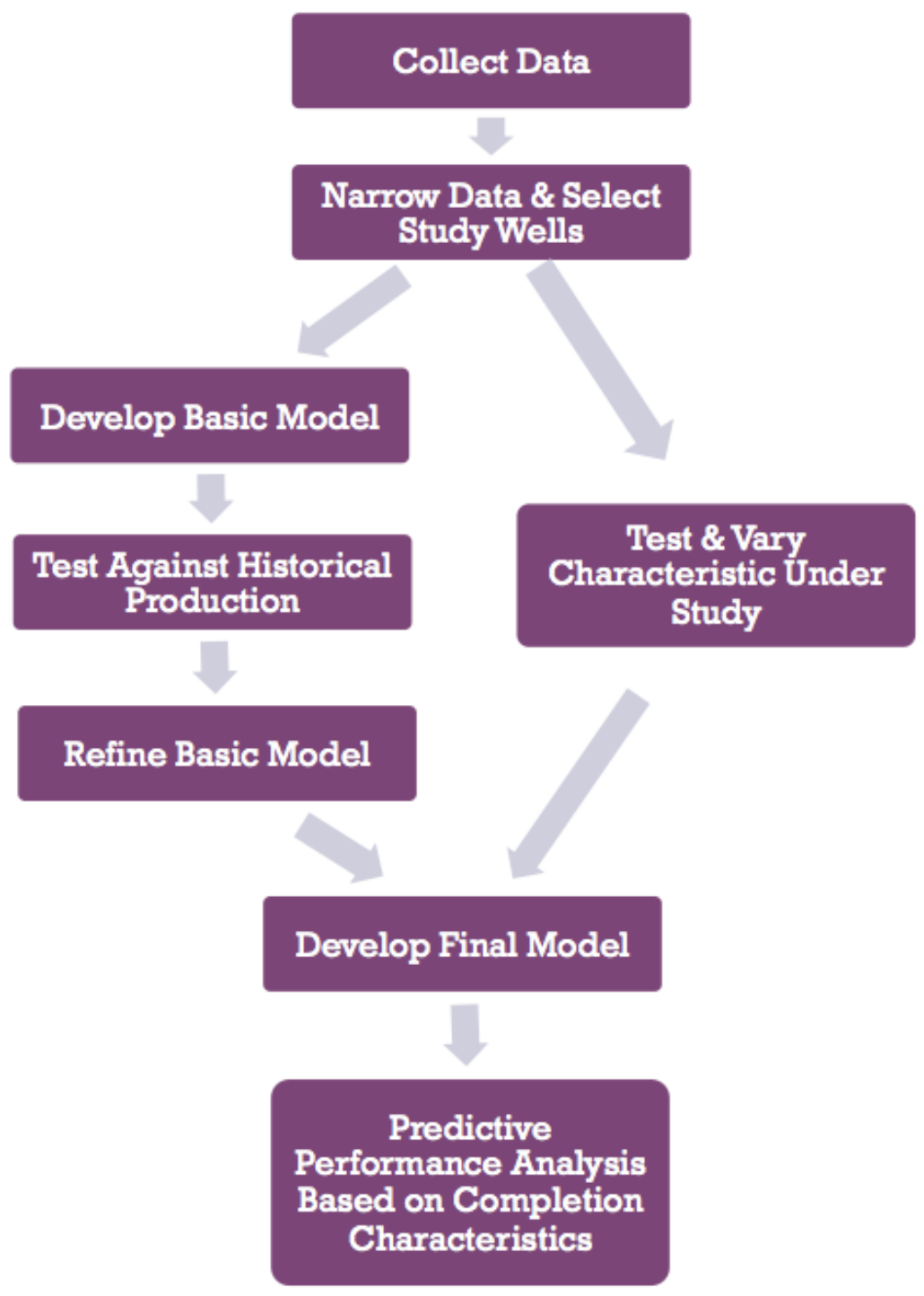

Figure 3.1: Methodology Flowchart. 


\section{Chapter 4}

\section{Results and Discussions}

\section{Section 4.1: Data Collection}

All electronically available completion and production information was collected for horizontal Marcellus Shale wells in West Virginia and Pennsylvania. Table 4.1 below shows the statistics of the data set collected for all horizontal Marcellus Shale wells.

Table 4.1: Initial data set.

\begin{tabular}{ccc}
\hline Data Statistic & West Virginia & Pennsylvania \\
\hline Permitted Horizontal Wells & 387 & 2,803 \\
Completion Reported & 103 & 683 \\
Production Reported & 71 & 1,016 \\
Operators & 13 & 28 \\
Counties & 10 & 27 \\
\hline
\end{tabular}

In West Virginia, completions data was gather from the database website, West Virginia Copy, www.wvcopy.com. Every individual completion form for each well was compiled into a Microsoft Excel database manually. The data was current as of July 2011. Production information in West Virginia was gathered as published on the website of West Virginia Department of Environmental Protection Office of Oil and Gas, www.dep.wv.gov/oil-and-gas. The most recent production information in West Virginia was current as of December 2010.

Table 4.2: Initial data set technical data averages

\begin{tabular}{ccc}
\hline Statistical Average & West Virginia & Pennsylvania \\
\hline Vertical Depth & $7,030 \mathrm{ft}$ & $7,247 \mathrm{ft}$ \\
\hline Measured Depth & $11,311 \mathrm{ft}$ & $10,754 \mathrm{ft}$ \\
\hline Lateral Length & $3,309 \mathrm{ft}$ & $3,385 \mathrm{ft}$ \\
\hline Number of Stages & 10.4 & 10.2 \\
\hline Stage Length & $357 \mathrm{ft}$ & 343 \\
\hline Total Water Volume & $103,482 \mathrm{bbl}$ & $93,302 \mathrm{bbl}$ \\
\hline Total Sand Volume & $4,064,032 \mathrm{lbs}$ & $4,226,242 \mathrm{lbs}$ \\
\hline Pumping Rate & $87.6 \mathrm{bpm}$ & $73.4 \mathrm{bpm}$ \\
\hline
\end{tabular}


Similarly in Pennsylvania, completions and production information was gathered on a well-bywell basis through the Pennsylvania Internet Record Imaging System (PA IRIS) ONBASE server at www.pairis.state.pa.us/dcnr/. Completion data was reported up to August 2011 and production data was reported up to December 2011.

Generalized trends were examined from this large initial data set in order to gain a better understanding of the type of completion styles that were being used by operators basin-wide. As shown in Table 4.2, technical data given in this large data set provides a baseline for understanding the broad range of fracturing parameters being used by operators. Slight variations seen between the data average for each state can be primarily attributed to the depth and rock property differences present in the different areas of the Marcellus Shale. Figure 4.1 represents on an individual basis the information averaged in Table 4.2 and arranged by date. It is easily observable that the completion trends have changed as a function of time. This can be related to an increased understanding of the reservoir and an improvement in drilling and stimulation technologies as more wells have been drilled into the shale. It is now possible to drill longer wells, some over 6,000 feet long, thus enabling more hydraulic fracturing stages to be completed. It is interesting to note that stage lengths have slightly decreased since the first wells were drilled in 2007. The effect of stage length on lifetime production will be addressed later in this study. Included in Appendix A are graphs showing the sand amount versus date (Figure A1), the volume of fluid versus date (Figure A2), and the average pumping rate versus date (Figure A3).

Also of interest is the location and density of the activity in both West Virginia and Pennsylvania. Figure 4.2 shows the number of horizontal Marcellus Shale wells completed by county and state. This shows that the northern panhandle of West Virginia is very active, which could be contributed to the fact that there is wet gas is this region. As expected, counties located in the "hot spot" regions of Pennsylvania as discussed above in Figure 1.2 are the major targets of drilling. Figure 4.2 also illustrates that the activity has been more widespread in Pennsylvania than it has been in West Virginia. 


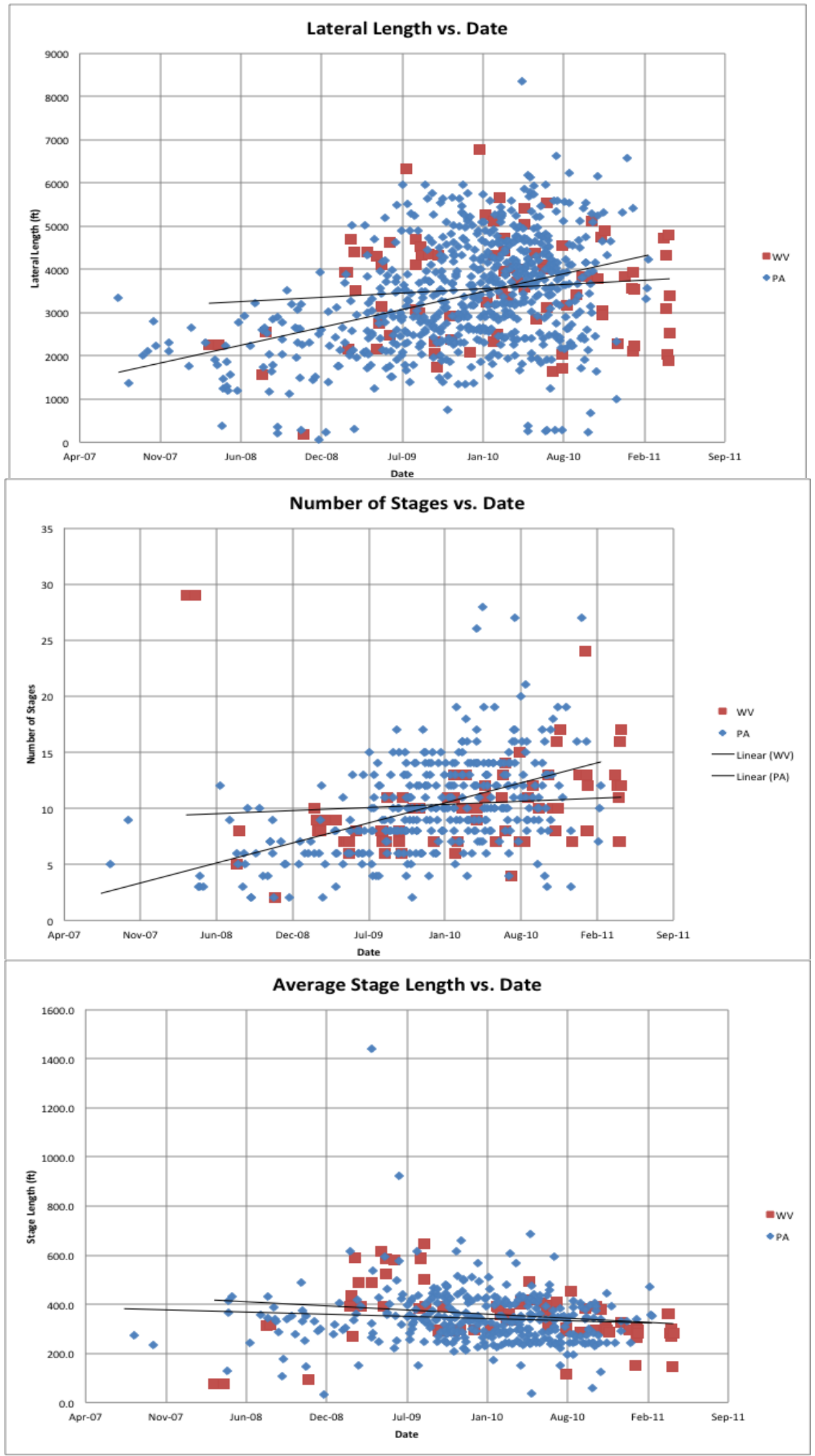

Figure 4.1: Technical well data statistics versus date.. 


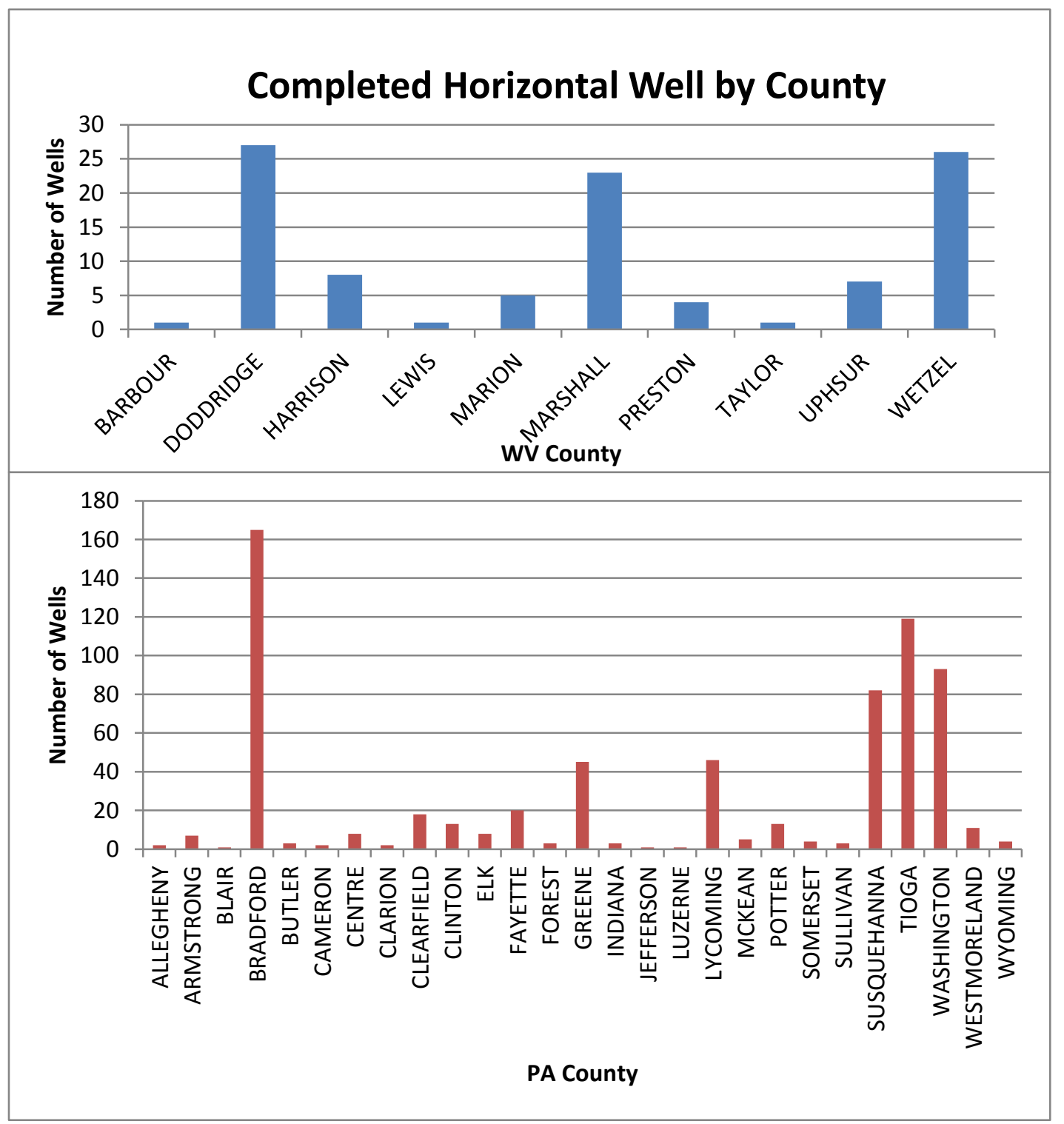

Figure 4.2: Completed horizontal wells by county and state.

\section{Section 4.2- Narrowing Data and Selecting Study Wells:}

After the initial data was collected, criteria were defined in order to narrow the data set and choose specific wells to history match. First, the well was required to have both reported production and completions data. Secondly, in order to be able to perform history matching later in the study, wells were required to have at least two years of reported production data. Third, the reported completions data had to contain the number and length of fracturing stages, the sand 
volume and mesh sizes used, and the amount of water used during hydraulic fracturing. These three criteria eliminated a large number of wells in the initial data set. Next, this smaller group of wells was mapped. Wells that were not geographically located near other horizontal Marcellus Shale wells were eliminated. From this, a small group was defined for four different areas and will be discussed in further detail later. Finally, the production from this group was further examined in order to determine that a normal production trend was present, and that the production had not been noticeably impacted by outside, uncontrollable conditions, such as pipeline availability.

Following this detailed elimination process, twenty-six horizontal Marcellus Shale wells were chosen as the final study group. These wells represent the Marcellus Shale in four different areas-Greene County, Pennsylvania; Lycoming County, Pennsylvania; Susquehanna County, Pennsylvania; and Wetzel County, West Virginia. Table 4.3 provides a detailed summary of the range of the fracturing parameters that were present in the final study group. Figure 4.3 shows the geographic location of each of the Greene County, Pennsylvania and Wetzel County, West Virginia study wells. Additional maps of the Lycoming County (Figure A4) and Susquehanna County (Figure A5) wells are included in Appendix A.

Table 4.3: Range of fracturing parameters in final study group.

\begin{tabular}{ccc}
\hline Parameter & Maximum & Minimum \\
\hline Lateral Length (feet) & 1,333 & 4,632 \\
Stage Length (feet) & 213 & 615 \\
Volume of Water (barrels) & 7,545 & 18,132 \\
Volume of Sand (pounds) & 250,355 & 979,820 \\
\hline
\end{tabular}




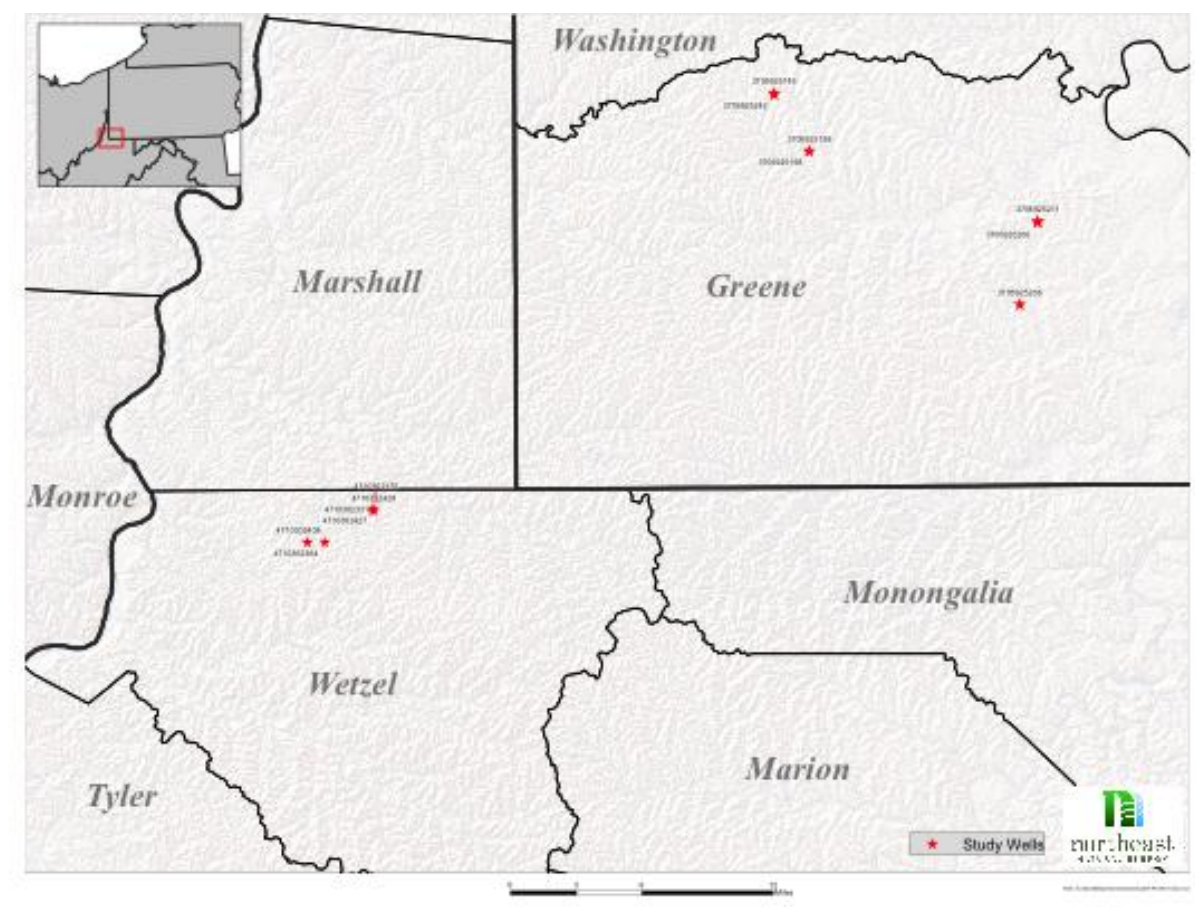

Figure 4.3: Map of Greene and Wetzel County study wells. (Courtesy of NNE).

\section{Section 4.3- Examining Characteristics Under Study:}

General comparisons were still possible in this smaller study group. Figure 4.4 shows comparisons of the critical fracturing parameters under examination in comparison to the actual production of these wells. With two years of production, neither Figure 4.4A nor 4.4B show a distinct relationship between the number or length of stages and the actual production. However, these charts represent that the data set chosen for further examination has a large range of fracture characteristics and associated production, which proved helpful in defining a model for a diverse group of wells. Figure 4.4C and 4.4D also show that there is no apparent relationship between the volume of water or sand used per stage during the stimulations and the gas production of the well at two years. These relationships are further examined later in this paper in relation to predicted production. 


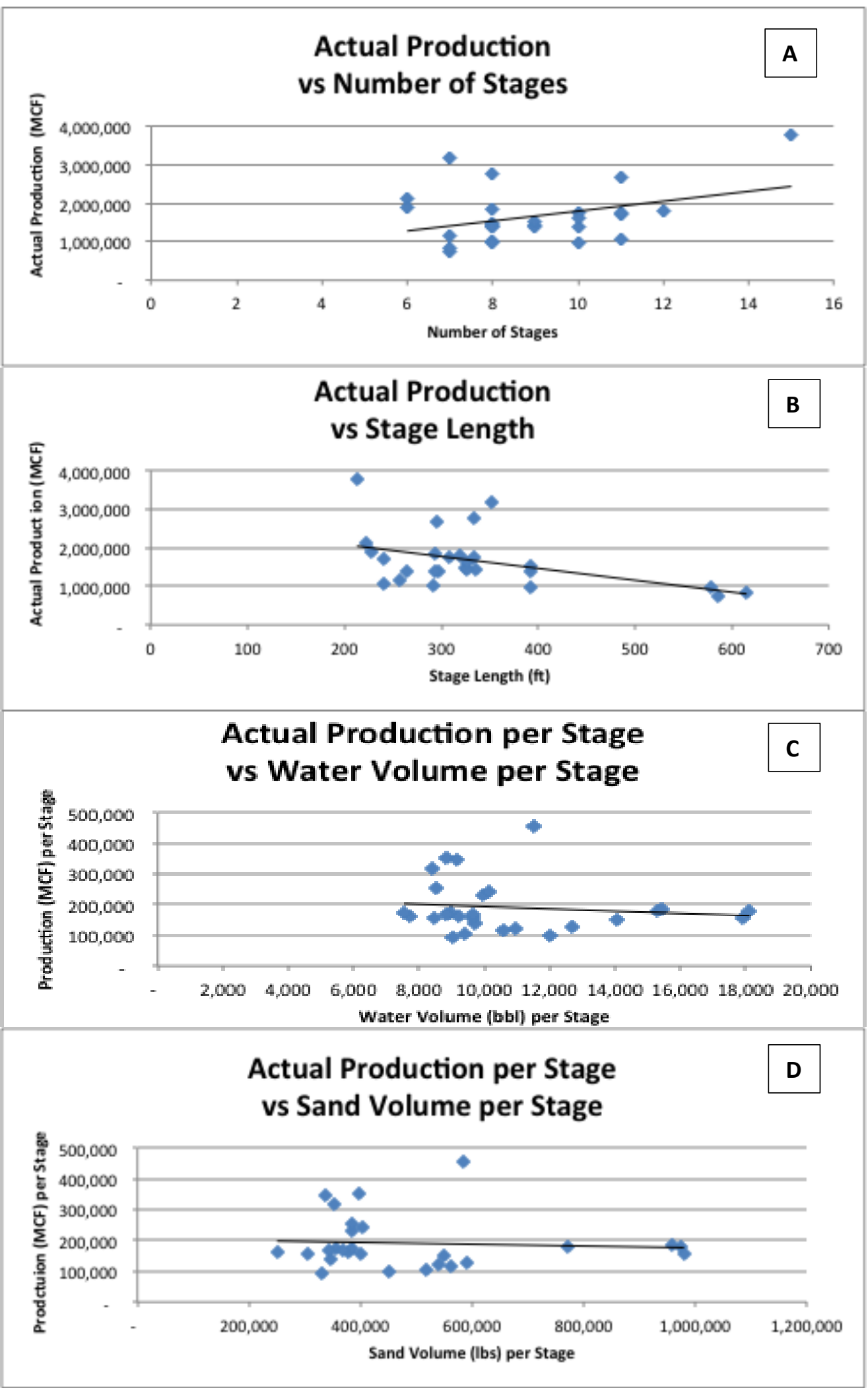

Figure 4.4. Fracturing parameters versus production. 


\section{Section 4.4- Development of Basic Model:}

As noted in the methodology section, the commercial reservoir simulator ECLIPSE, designed by Schlumberger, was used to evaluate these wells further. Reservoir simulation provides a method in which to predict the future performance of an individual well, in this case. Hossein Belyadi initially developed the base model originally used in this research (Belyadi, 2011). The model was constructed on the basis of a dual porosity system and adsorbed gas model. ECLIPSE has the ability to model horizontal wells with multi-stage hydraulic fractures, while also incorporating these shale specific properties. ECLIPSE is also very helpful in that it generates 3-D images of the well, reservoir, and hydraulic fractures, as shown in Figure 4.5.

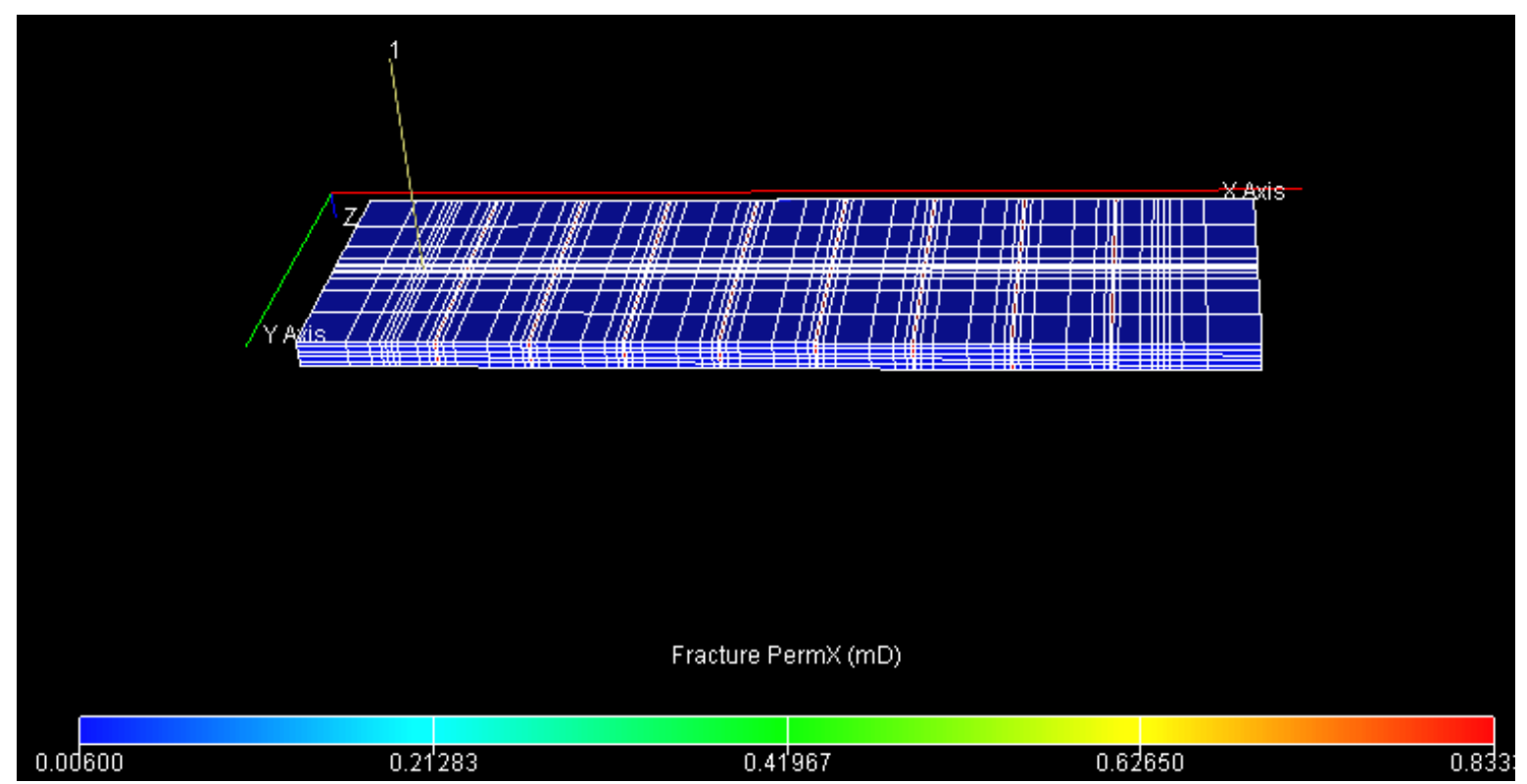

Figure 4.5: Model generated by ECLIPSE.

Table 4.4 shows all of the critical parameters that are needed to generate a predictive model in ECLIPSE. Obviously, several of these parameters, such as depth, thickness, lateral length, reservoir pressure, number of stages, and stage length, were varied based on the individual physical attributes of the particular well being studied. The parameters that were adjusted during the history matching process are designated in light purple in Table 4.4. These parameters will be further discussed in detail later. Formation thicknesses were determined for each county. In Greene County, pilot wells were already a part of the selected group, so actual 
Table 4.4: ECLIPSE base model parameters

\begin{tabular}{|c|c|c|}
\hline Base Parameters & Starting Value & Unit \\
\hline Depth & 7,000 & Feet \\
\hline Thickness & 75 & Feet \\
\hline N. Fracture Porosity & 0.002 & Fraction \\
\hline Matrix Porosity & 0.05 & Fraction \\
\hline N. Fracture Permeability & $0.002,0.002,0.0002$ & md \\
\hline Matrix Permeability & $0.0002,0.0002,0.0002$ & md \\
\hline Rock Compressibility & $1 \times 10^{-5}$ & 1/psia \\
\hline Density & 100 & $\mathrm{Lb} / \mathrm{ft}^{3}$ \\
\hline Reservoir Pressure & 3000 & psia \\
\hline Water Saturation & 0.15 & Fraction \\
\hline H. Fracture Half Length & 500 & $\mathrm{Ft}$ \\
\hline H. Fracture Width & 0.01 & In \\
\hline H. Fracture Porosity & 0.2 & fraction \\
\hline $\mathrm{P}_{\mathrm{wf}}$ & 500 & Psia \\
\hline Gas Diffusion Coefficient & 1 & $\mathrm{ft}^{2} /$ day \\
\hline H. Fracture Permeability & 20,000 & Md \\
\hline Stage Length & 250 & $\mathrm{Ft}$ \\
\hline
\end{tabular}

thickness measurements were used during modeling. In the remaining three counties, formation thickness was determined from publically available maps. For example, Figure 4.6 shows the thickness map used to determine the average thickness in Wetzel County, West Virginia. Figure A6, included in the Appendix is the thickness map used for the Pennsylvania counties. The following values were chosen to represent the reservoir thicknesses of the wells in each countyLycoming, 250 feet; Susquehanna, 175 feet; and Wetzel, 50 feet. Additionally, pressure gradients were gathered for each of the areas either directly from operators in the study area or from published maps and ranged from $0.49 \mathrm{psi} / \mathrm{ft}$ to $0.69 \mathrm{psi} / \mathrm{ft}$. 


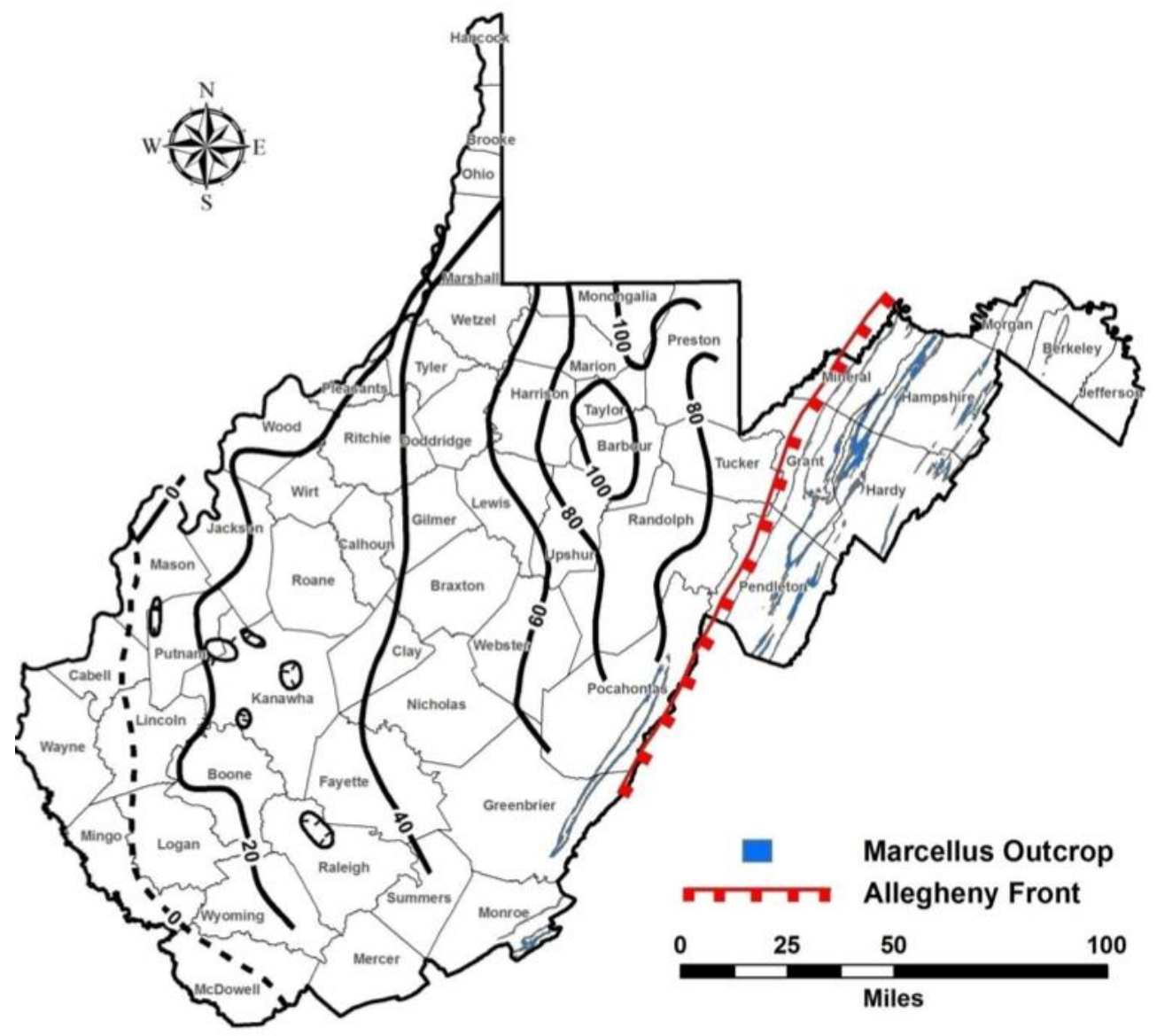

Figure 4.6: Marcellus Shale thickness map. (NETL, 2010).

\section{Section 4.5- Testing against Historical Production and Refining of Basic Model:}

Fourteen of the twenty-six wells in the study were chosen to be modeled using ECLIPSE. These wells were chosen based on certain characteristics that set them apart from the other wells, such as, but not limited to, large or small production, many stages, short stage lengths, or a large water to sand ratio.

Table 4.5 shows the wells that were chosen to be modeled along with the specific fracture characteristics of each well that this study examined. These wells were re-named based on their county name in order to protect operator information associated with API numbers. For example, study well G1 is located in Greene County. The number value assigned is completely arbitrary. 
The number of fracture stages per well ranged from 6 to 15 stages. Fracturing stage lengths varied from 213 feet in study well S1 to 586 feet in study well W3. In terms of water per stage, some operators used as little as 7,500 barrels during stimulation while other wells were fractured with almost 15,500 barrels per stage. Similarly, the sand per stage varied from 343,000 pounds to 960,000 pounds per stage. This wide range of parameters not only shows that that the industry is generally undecided on what individual parameters need to be, but that research is needed and necessary in this particular area in order to optimize the process.

Table 4.5: Fracture characteristics of modeled wells.

\begin{tabular}{|c|c|c|c|c|c|}
\hline ID & $\begin{array}{c}\text { \# Frac } \\
\text { Stages }\end{array}$ & $\begin{array}{c}\text { Stage Length } \\
\text { (ft) }\end{array}$ & Water (bb)/ Stage & Sand (lbs)/ Stage & Prod to Date (MCF) \\
\hline G1 & 11 & 295 & 10,164 & 402,431 & $2,657,992$ \\
\hline G2 & 8 & 296 & 8,949 & 355,068 & $1,380,134$ \\
\hline G3 & 7 & 258 & 8,844 & 343,637 & $1,162,212$ \\
\hline L1 & 10 & 309 & 15,278 & 772,280 & $1,771,329$ \\
\hline L2 & 8 & 325 & 15,428 & 959,878 & $1,480,622$ \\
\hline L3 & 8 & 292 & 12,695 & 592,138 & $1,033,018$ \\
\hline S1 & 15 & 213 & 8,556 & 385,500 & $3,771,317$ \\
\hline S2 & 6 & 222 & 8,859 & 397,809 & $2,101,892$ \\
\hline S3 & 8 & 294 & 7,545 & 385,750 & $1,373,854$ \\
\hline S4 & 10 & 326 & 9,221 & 378,435 & $1,601,791$ \\
\hline S5 & 7 & 351 & 11,532 & 585,657 & $3,168,380$ \\
\hline W1 & 9 & 391 & 9,648 & 367,566 & $1,504,675$ \\
\hline W2 & 8 & 579 & 10,936 & 538,566 & 971,924 \\
\hline W3 & 7 & 586 & 10,613 & 560,846 & 742,707 \\
\hline
\end{tabular}

\section{Section 4.6- Development of Final Model:}

All fourteen of these wells were modeled using ECLIPSE. Multiple runs were required for each well to ensure that the predicted production of the well matched the reported production. The drainage area of each well was modeled so that the reservoir had a four to one length to width ratio. However, one thousand feet was set as the minimum width of a reservoir, no matter 
what the length. In addition to this, in the case of Greene and Wetzel counties, where the Marcellus is less than 100 feet thick, the well bore was placed in the center of the formation, and the fracture height was defined to be that same thickness. In Lycoming and Susquehanna counties, the Marcellus Shale is considerably thicker. It is well know that the majority operators place the well bores in these counties in the lower, more organic rich section of the shale. For this reason, all wells in Lycoming and Susquehanna counties were modeled with the wellbore being placed in the center of the bottom 100 feet of the Marcellus. The fracture height was limited to that lower section of 100 feet as well. In order to match the predicted production to the actual recorded production of each individual well, three parameters were varied. A detailed list is shown in Figure 4.7. First, the fracture half-length was determined to be most representative when modeled between 275 feet and 500 feet. This parameter alone drastically impacted the predicted production curve. Variation of fracture half length caused the predicted production curve to shift along the y-axis. Secondly, the natural fracture permeability (also known as Bulk X-direction Permeability ranged between 0.002 millidarcy to 0.02 millidarcy (md). This parameter greatly affected the production of the well after it had been active for several years. It is important to note that the majority of study wells had what would be considered "normal" natural fracture permeability between $0.002 \mathrm{md}$ and $0.004 \mathrm{md}$. Lastly, varying the hydraulic

\begin{tabular}{|c|c|c|c|c|c|}
\hline Well ID & $\begin{array}{c}\text { Fracture } \\
\text { Half } \\
\text { Length (ft) }\end{array}$ & $\begin{array}{c}\text { Bulk } \\
\text { X-direction } \\
\text { Perm (md) }\end{array}$ & $\begin{array}{c}\text { Fracture } \\
\text { Porosity }\end{array}$ & $\begin{array}{c}\text { Initial Back } \\
\text { Pressure } \\
\text { (psi) }\end{array}$ & $\begin{array}{c}\text { Back Pressure } \\
\text { after 3 } \\
\text { months (psi) }\end{array}$ \\
\hline G1 & 500 & 0.010 & 0.20 & 250 & 250 \\
G2 & 350 & 0.002 & 0.10 & 1000 & 500 \\
G3 & 300 & 0.004 & 0.20 & 850 & 350 \\
\hline L1 & 400 & 0.003 & 0.20 & 750 & 400 \\
L2 & 500 & 0.010 & 0.10 & 300 & 250 \\
L3 & 300 & 0.002 & 0.10 & 800 & 500 \\
\hline S1 & 500 & 0.004 & 0.20 & 700 & 550 \\
S2 & 500 & 0.015 & 0.20 & 250 & 250 \\
S3 & 275 & 0.002 & 0.10 & 1000 & 1000 \\
S4 & 275 & 0.002 & 0.10 & 1000 & 850 \\
S5 & 500 & 0.020 & 0.20 & 250 & 250 \\
\hline W1 & 500 & 0.004 & 0.20 & 500 & $500^{*}$ \\
W2 & 500 & 0.002 & 0.10 & 1000 & $400^{*}$ \\
W3 & 400 & 0.002 & 0.10 & 1000 & $800^{*}$ \\
\hline
\end{tabular}

Figure 4.7. Model parameters varied during history matching. 
fracture porosity from $10 \%$ to $20 \%$ affected the initial production of the well. In general, the model over predicted the initial production of the well because it assumed that the entire space occupied by proppant was completely filled by free gas that would be produced essentially instantaneously. In actuality, this space is occupied by water remaining from the stimulation process that has not yet been removed from the wellbore. Additionally, back pressure was incorporated into the model to account for any pipeline or flow restrictions and to adjust for the pressure created by flowback water being produced during the initial production period. Typically, for the first three months of a wells production, the back pressure was kept relatively high, in order match the actual first production data. After three months, the model relaxed pressure to allow for more normal flow conditions. For the cases in Wetzel County, the back pressure was reduced after the shut-in period.

For example, daily flow rate and cumulative production curves for study well S2 are shown in Figure 4.8. Actual production values are shown in red while model generated predicted

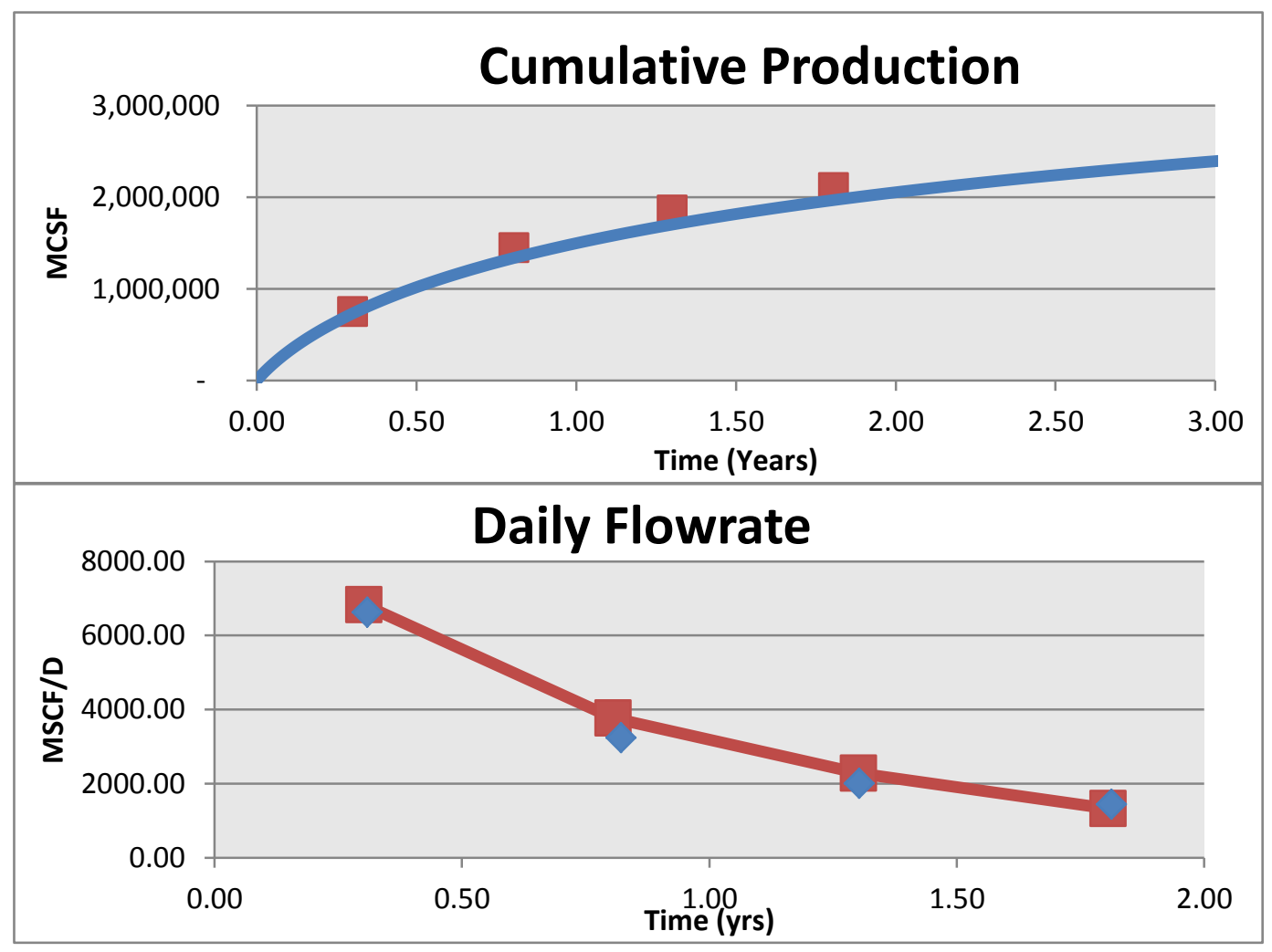

Figure 4.8: Study well S2 daily flow rate and cumulative production curves. 
production is shown in blue. It is important to note that production data submitted to Pennsylvania was in the form of a six-month cumulative value. For this reason, only four actual production data points appear in the graph. Simple, mathematical adjustments were made in order to compare these values on an million cubic feet per day (MCF/D) level. However, in West Virginia, production was reported on a monthly basis. It is easily recognizable that the model does an almost perfect job of matching the actual production data points. All models were designed to generate predicted production values out to ten years from the initial production. Figure A7 and A8 included in Appendix A are the daily flow rate and cumulative production charts for well W3. This particular curve is interesting because the study wells in Wetzel County experienced a two to three month shut in period after initial production. The model was able to easily account for this shut in period, thus showing the versatility of predictive reservoir modeling and this model in particular. Appendix B contains the daily flow rate and cumulative production curves for every well that was modeled in this study.

Table 4.6 shows the results of the modeling in terms of actual production, predicted fiveyear cumulative production ("cum prod"), and ten year predicted cumulative production. In this Table, the green shading represents the highest values, yellow the intermediate values, and red the lowest values. This table is color coded by county to emphasize the best and worst producers in each county and observe the trends associated with each. More importantly and representative,

Table 4.6: Modeling cumulative results

\begin{tabular}{|ccc|c|c|}
\multicolumn{1}{c}{ Well ID } & $\begin{array}{c}\text { Prod to } \\
\text { Date }\end{array}$ & $\begin{array}{c}\text { 1 yr ACTUAL } \\
\text { Production }\end{array}$ & $\begin{array}{c}\text { Pred (5 yr) } \\
\text { Cum Prod }\end{array}$ & $\begin{array}{c}\text { Pred (10 yr) } \\
\text { Cum Prod }\end{array}$ \\
\hline G1 & $2,657,992$ & $2,024,032$ & $3,343,115$ & $3,734,306$ \\
G2 & $1,380,134$ & 808,981 & $1,975,353$ & $2,340,294$ \\
G3 & $1,162,212$ & 643,412 & $1,662,640$ & $1,940,938$ \\
\hline L1 & $1,771,329$ & $1,102,404$ & $2,890,189$ & $4,000,269$ \\
L2 & $1,480,622$ & $1,139,395$ & $2,908,553$ & $3,919,399$ \\
L3 & $1,033,018$ & 645,693 & $1,965,755$ & $2,803,629$ \\
\hline S1 & $3,771,317$ & $2,494,387$ & $5,451,907$ & $6,526,425$ \\
S2 & $2,101,892$ & $1,569,796$ & $2,803,669$ & $3,286,880$ \\
S3 & $1,373,854$ & 796,348 & $2,570,427$ & $3,428,411$ \\
S4 & $1,601,791$ & 851,743 & $3,425,960$ & $4,649,053$ \\
S5 & $3,168,380$ & $1,693,612$ & $4,550,500$ & $5,568,024$ \\
\hline W1 & $1,504,675$ & 901,219 & $1,871,641$ & $2,208,538$ \\
W2 & 971,924 & 667,845 & $2,030,529$ & $2,745,825$ \\
W3 & 742,707 & 484,072 & $1,566,860$ & $2,123,513$ \\
\hline
\end{tabular}


Table 4.7 shows the data for each of the wells on a per stage basis. It is much easier to draw comparisons and examine the data from each well when based on the number of stages. Many observations can be drawn from this information, and will be discussed further in the form of charts and graphs related to the individual fracture parameters under study. Table 4.7 shows that the number of stages does not necessarily correlate to increased production over the lifetime of the well. Study well S1, for example, has the most fracture stages in the study, but it does not have the best production. Table 4.6 shows that this well experienced a huge influx of gas at the beginning of its life (most likely due to a high concentration of natural fractures already present in the formation), but in terms of effectiveness of the stimulation, this wells predicted production at ten years per stage is very low in comparison.

Table 4.7: Modeling results based on number of stages.

\begin{tabular}{|c|c|c|c|c|c|}
\hline Well ID & $\begin{array}{l}\text { \# Frac } \\
\text { Stages }\end{array}$ & $\begin{array}{l}\text { Actual Prod/ } \\
\text { \# Frac Stages }\end{array}$ & $\begin{array}{l}\text { ACTUAL } \\
\text { Prod/ \# } \\
\text { Stages }\end{array}$ & $\begin{array}{l}\text { Pred Prod } \\
\text { (5 yr)/ \# Frac } \\
\text { Stages }\end{array}$ & $\begin{array}{l}\text { Pred Prod } \\
(10 \mathrm{yr}) / \# \\
\text { Frac Stages }\end{array}$ \\
\hline G1 & 11 & 241,636 & 184,003 & 303,920 & 339,482 \\
\hline $\mathrm{G} 2$ & 8 & 172,517 & 101,123 & 246,919 & 292,537 \\
\hline G3 & 7 & 166,030 & 91,916 & 237,520 & 277,277 \\
\hline $\mathrm{L} 1$ & 10 & 177,133 & 110,240 & 289,019 & 400,027 \\
\hline L2 & 8 & 185,078 & 142,424 & 363,569 & 489,925 \\
\hline L3 & 8 & 129,127 & 80,712 & 245,719 & 350,454 \\
\hline S1 & 15 & 251,421 & 166,292 & 363,460 & 435,095 \\
\hline S2 & 6 & 350,315 & 261,633 & 467,278 & 547,813 \\
\hline S3 & 8 & 171,732 & 99,544 & 321,303 & 428,551 \\
\hline S4 & 10 & 160,179 & 85,174 & 342,596 & 464,905 \\
\hline S5 & 7 & 452,626 & 241,945 & 650,071 & 795,432 \\
\hline W1 & 9 & 167,186 & 100,135 & 207,960 & 245,393 \\
\hline W2 & 8 & 121,491 & 83,481 & 253,816 & 343,228 \\
\hline W3 & 7 & 106,101 & 69,153 & 223,837 & 303,359 \\
\hline
\end{tabular}

\section{Section 4.7- Predictive Performance Analysis Based on Completion Characteristics:}

The first fracture parameter under review is the effect of the number of stages on the production of a horizontal Marcellus Shale well. Figure 4.9 shows the results from the fourteen simulated wells. Ten year production was designated in the figure by the blue diamonds while the five year production is designated by the red squares. 
Figure 4.10 below shows the plot of kh versus the ten year predicted production of the modeled wells. The permeability $(\mathrm{k})$ graphed is the natural fracture permeability (x-direction) and the height $(\mathrm{h})$ is the total formation height. This graph shows that there is a loose relationship between this derived value of permeability and height. This could be due to the fact that two of the four areas studied had very thick sections of Marcellus Shale.

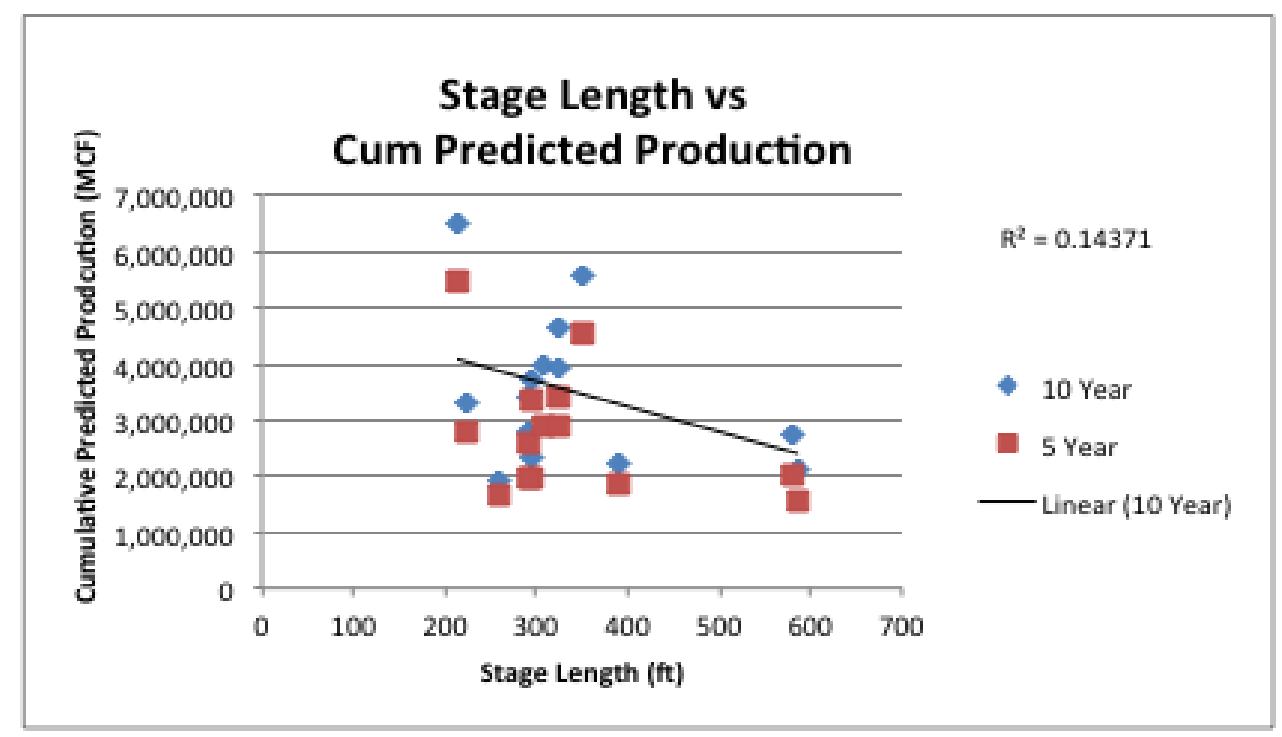

Figure 4.9: Stage length versus cumulative predicted production.

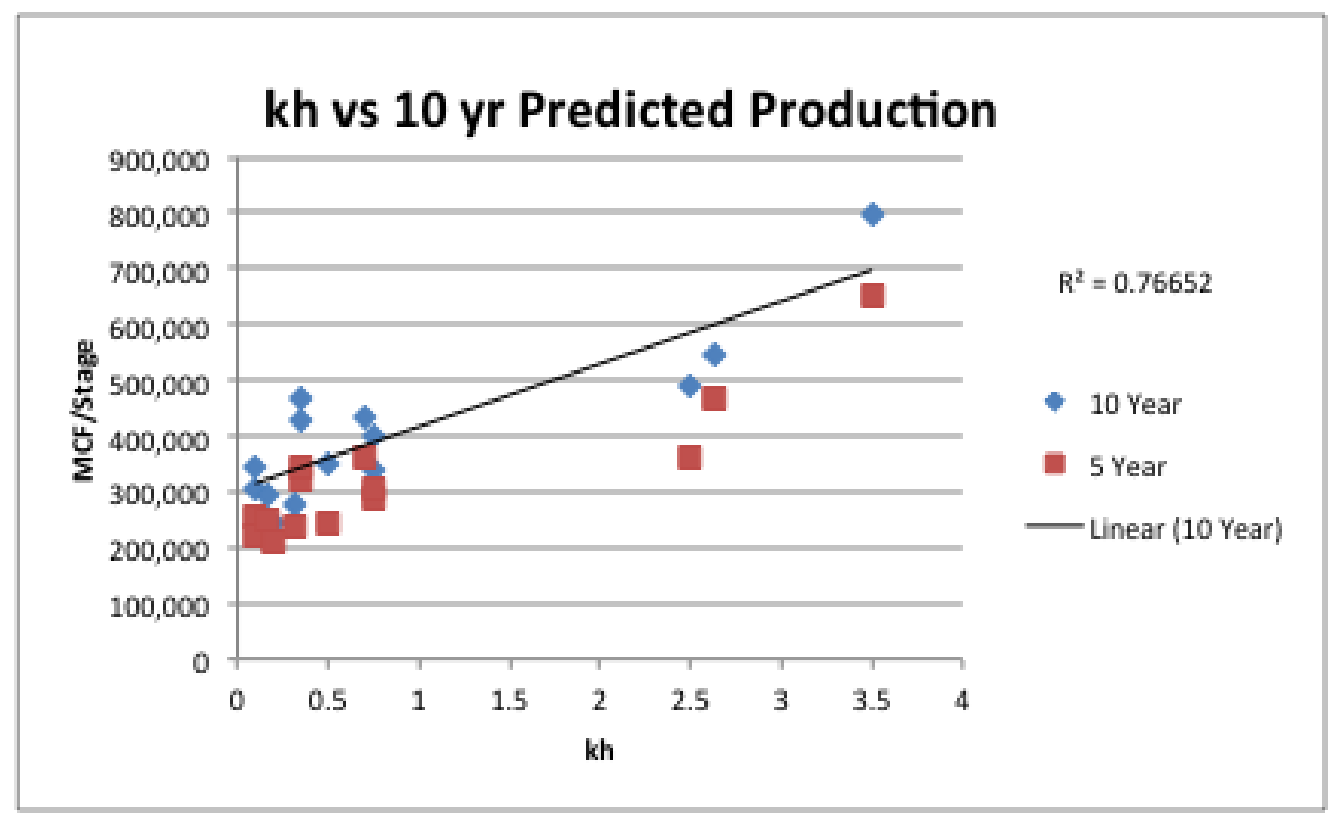

Figure 4.10: kh versus 10 year predicted production. 
The next fracture parameter under investigation was the amount of water used to stimulate a well per stage. Figure 4.11 demonstrates this parameter in relation to the production per stage at three different time periods, including the one year actual production. There is no observable correlation after the first year of actual production. However, a trend become observable after five years and is even more definitive after ten years of production. To further examine this relationship, a similar graph showing just Greene and Lycoming counties is included in Appendix A. In that case, the linear correlation is even higher at eighty three percent. Furthermore, it is important to note that Figure 4.11 only shows the data for wells in Greene County, Pennsylvania, Lycoming County, Pennsylvania, and Wetzel County, West Virginia. This is due to the fact that the pressures observed in Susquehanna County, Pennsylvania were so significantly higher than the three other areas that the predictions in that area were scaled differently, even though there is an identifiable relationship between the wells in this county collectively. Figure A9 showing the relationship in Susquehanna County may be found in Appendix A.

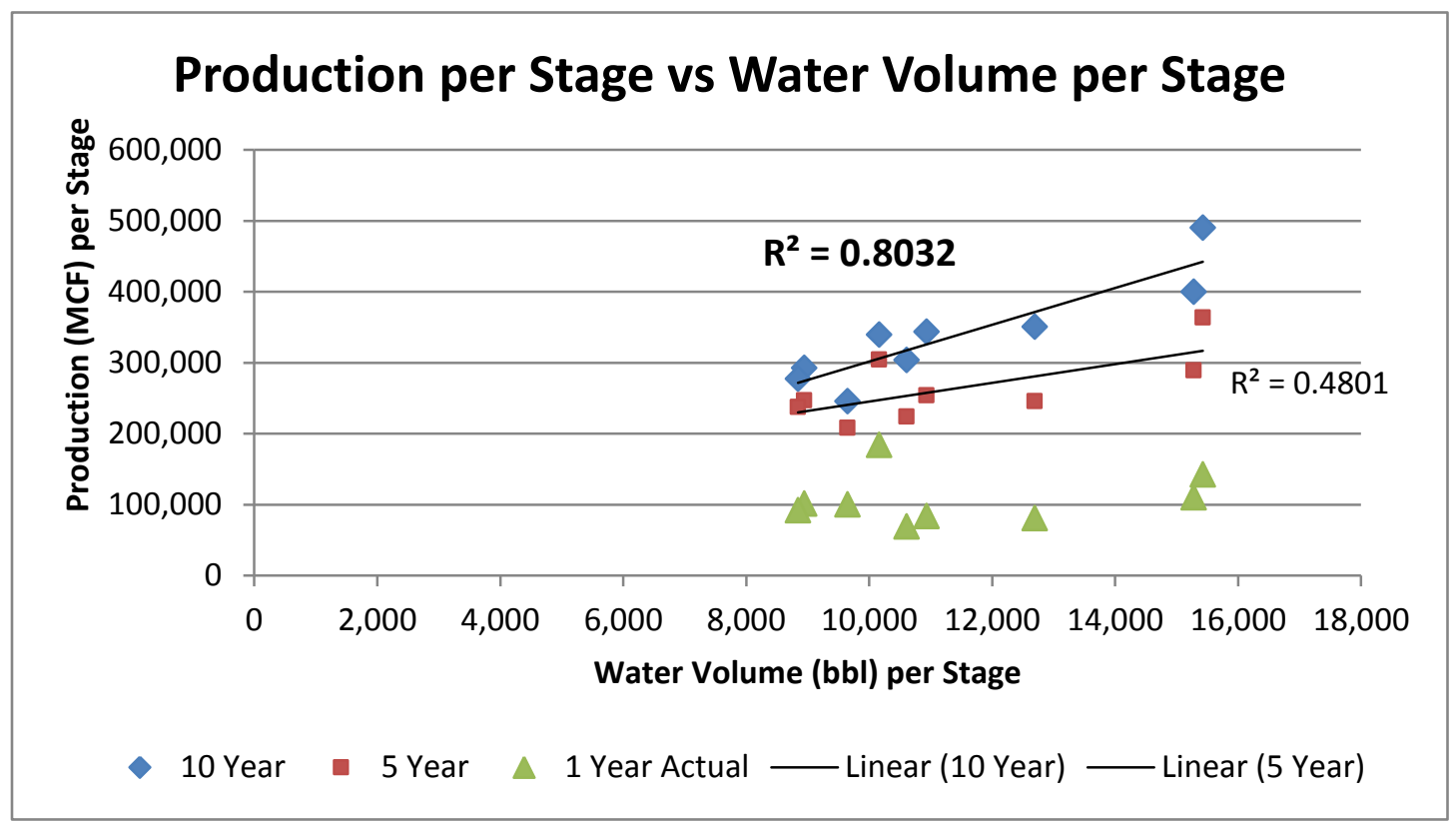

Figure 4.11: Production per stage versus water volume per stage.

Similar to the examination of water usage, Figure 4.12 shows the relationship between the natural gas production per stage and the sand volume used to stimulate the well per stage. Similar correlation trends are observed with the amount of sand used as with the amount of water 
used. For the same reasons as with the water volumes, Figure 4.12 only includes the data from study wells in Greene, Lycoming, and Wetzel counties. In Appendix A, Figure A10 showing this same relationship for just Greene and Lycoming counties is accessible. The correlation is much stronger when just these counties are compared-- $93.6 \%$ linear.

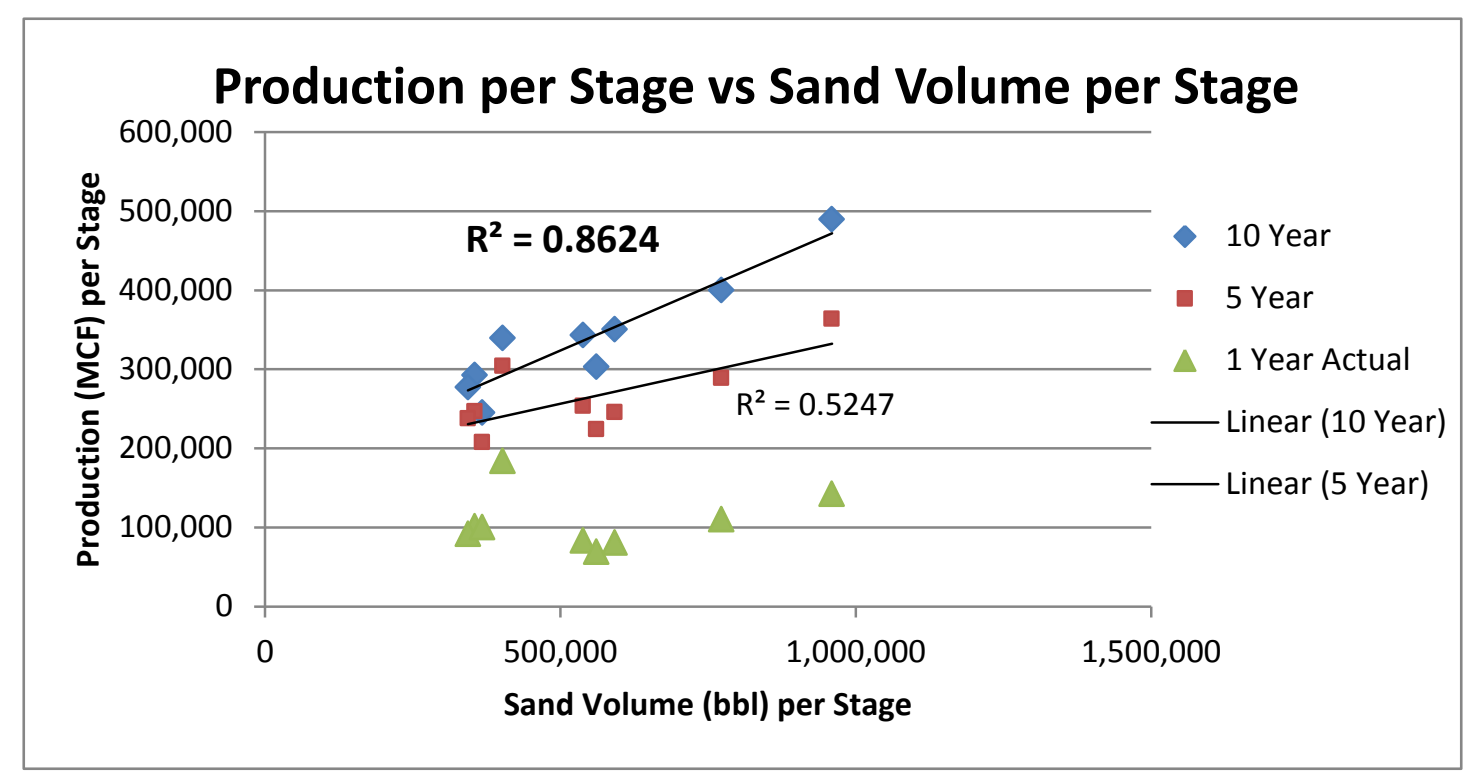

Figure 4.12: Production per stage versus sand volume per stage.

One final relationship of interest is the sand versus water ratio. Figure 4.13 shows this relationship plotted against incremental time period production, as before. As would be expected, the same trend appears as in the cases with just the water and just the sand. As time increases, the correlation between the ratio and the production strengthens. 


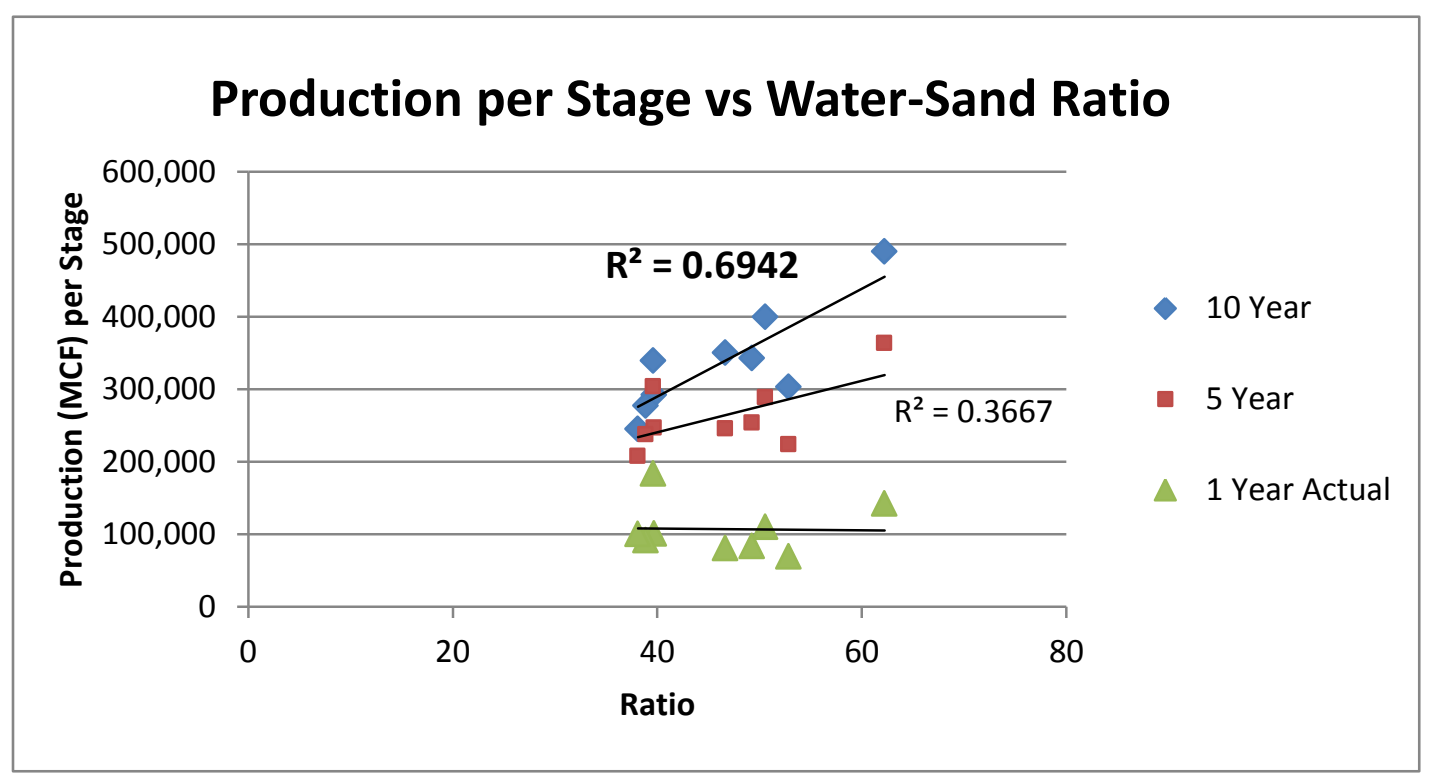

Figure 4.13: Production per stage versus water-sand ratio. 


\section{Chapter 5}

\section{Summary and Conclusions}

In summary, this study has successfully achieved the goals defined. In regards to the refinement and design of the reservoir model, the following outcomes are true:

- New model can successfully replicate past production behavior

- Fracture half-length, hydraulic fracture permeability, and natural fracture permeability have been identified as key, curve-adjusting parameters

- Accurate history matching was performed for wells in four different regions of the Marcellus Shale

- Various well events, such as shut in periods, can be incorporated into the model

Additionally, it also became very apparent that the initial reservoir pressure was a huge factor in the prediction of production and thus affected the conclusions that could be drawn as well as the comparisons among different regions.

While studying and analyzing the fracture parameters chosen to be examined during this study, the following conclusions were drawn involving the number and spacing of stages.

- Number of stages significantly impacted initial production

- As the number of stages increased, initial production increased

- As the stage length decreased, initial production increased

- Short stage lengths do not promote greater recovery

The relationship between stage length and initial production could be explained in part by the fact that more fractures are being created close to the wellbore, thus increasing the initial flow of hydrocarbons. The predicted production provided by the modeling suggested that the stage length may affect the production up to five years. Shorter spacing may also allow for overlapping, condensed fractures, thus affecting the initial production, but not accessing the full extent of the reservoir, and thereby not impacting the recovery. It may be concluded that average size stage lengths, around 300 feet, provide an acceptable recovery as well as economic efficiency in developing a reserve. 
Both the volume of water per stage and the amount of sand per stage used during hydraulic fracturing had similar trends when related to lifetime production, as follows:

- Initial production was not affected by the volume of sand or water

- Increased water/sand resulted in increased long term (ten-year) production

- The correlation strengthened with time

In the case of the volume of water per stage, the trend could possibly be explained by the fact that increased water volumes may be able to dissolve more minerals that have previously closed up natural fractures, thus producing more permeability in the areas in which the water contacts. More water would allow for more flushing of the minerals, and increased contact with new natural fractures, thus explaining the higher natural fracture permeability obtained from the history matching which leads to long-term production increase. 


\section{Chapter 6}

\section{Recommendations}

For further work, it is recommend to expand the study to more areas in the Marcellus Shale. Now that a seemingly comprehensive model has been developed and the specific parameters that need to be adjusted to model a well are better understood, it would be much easier to study more areas. Expansion of the study group would also confirm the results of this research and expand the understanding of the relationships of the fracture parameters.

Secondly, it is recommend to investigate and identify an optimized stage length. This question alone is one of the most important factors in the design of a well stimulation operation. An optimized stage length could greatly affect not only the way company designs their well completions, but could also provide for more lifetime recovery for a well. Further, it would be very beneficial to further study the relationship between water and sand volumes and the productivity of a well. This research shows a definite correlation, but an optimized value or function was not defined.

Finally, it is recommend to study several other fracture parameters and their relationship to the lifetime production of a well. These would include the sand mesh sizes and combinations, perforation cluster spacing, and the fluid-pumping rate. 


\section{Bibliography}

Belyadi, H. (2011). Production analysis of marcellus shale. (Master's thesis, West Virginia University).

DOE. (2004, June). Hydraulic Fracturing White Paper.

EIA. (2008, November). Map of shale gas basins in the united states. Retrieved from http://energyindustryphotos.com/shale_gas_map_shale_basins.htm

Engelder, T. (2009). Marcellus. Basin Oil \& Gas Magazine, Aug(2009), 18-22. Retrieved from http://marcellus.psu.edu/resources/PDFs/marcellusengelder.pdf

Marcellus shale - appalachian basin natural gas play. (2012). Retrieved from http://geology.com/articles/marcellus-shale.shtml

Net feet of organic-rich shale in marcellus shale formation. (2010, February). Retrieved from http://www.dcnr.state.pa.us/topogeo/oilandgas/images/Marcellus_Isopleth.pdf

NETL. (2010). Projecting the economic impact of marcellus shale gas development in west virginia: A preliminary analysis using publicly available data. National Energy Technology Laboratory, Retrieved from www.netl.doe.gov/energyanalyses/.../WVMarcellusEconomics3.pdf

Virginia department of mines minerals and energy division of oil and gas. (2006). Retrieved from http://www.dmme.virginia.gov/DGO/documents/HydraulicFracturing.shtml

What is hydraulic fracturing?. (2012). Retrieved from http://www.propublica.org/special/hydraulic-fracturing-national 


\section{Appendix A}

All figures contained in this appendix are discussed in detail throughout the body of the paper. However, a brief explanation will be offered here.

Figure 1A below represents the amount of sand injected per well versus data for the entire data set collected. Figure A2 represents this same trend but in respect to the volume of fluid used per well. Both of these data sets basically illustrate that the size of stimulations being performed in the Marcellus Shale has gotten larger with time. This is most likely due to the fact that in general, the horizontal wells are getting longer, thus allowing for more fracturing stages, and therefore resulting in a larger overall amount of sand used.

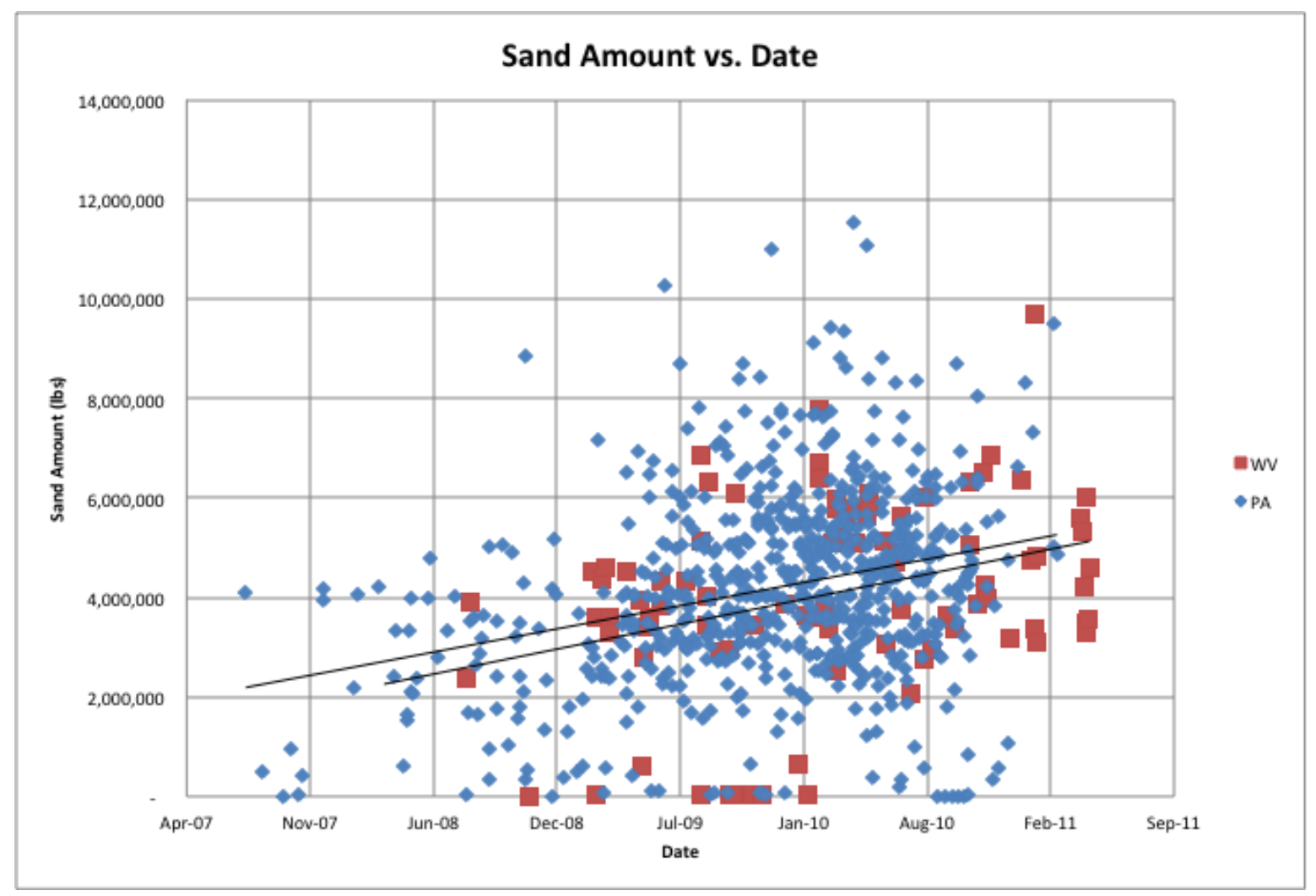

Figure A1 


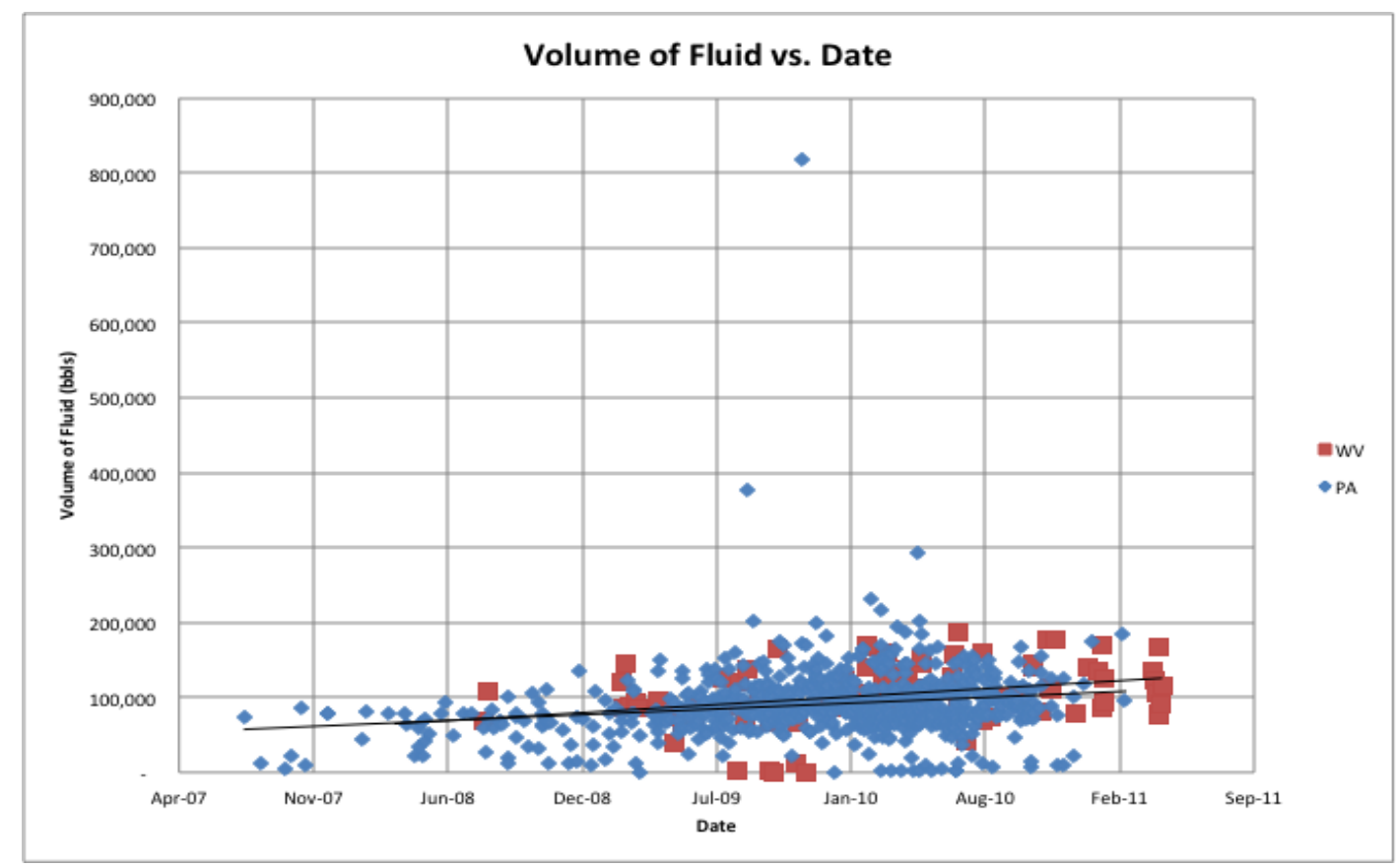

Figure A2

Figure A3 is a representation of this same data set in regards to the average pumping rate during hydraulic fracturing and date. This figure is included in order to give a general idea of the pump ranges that operators are currently using.

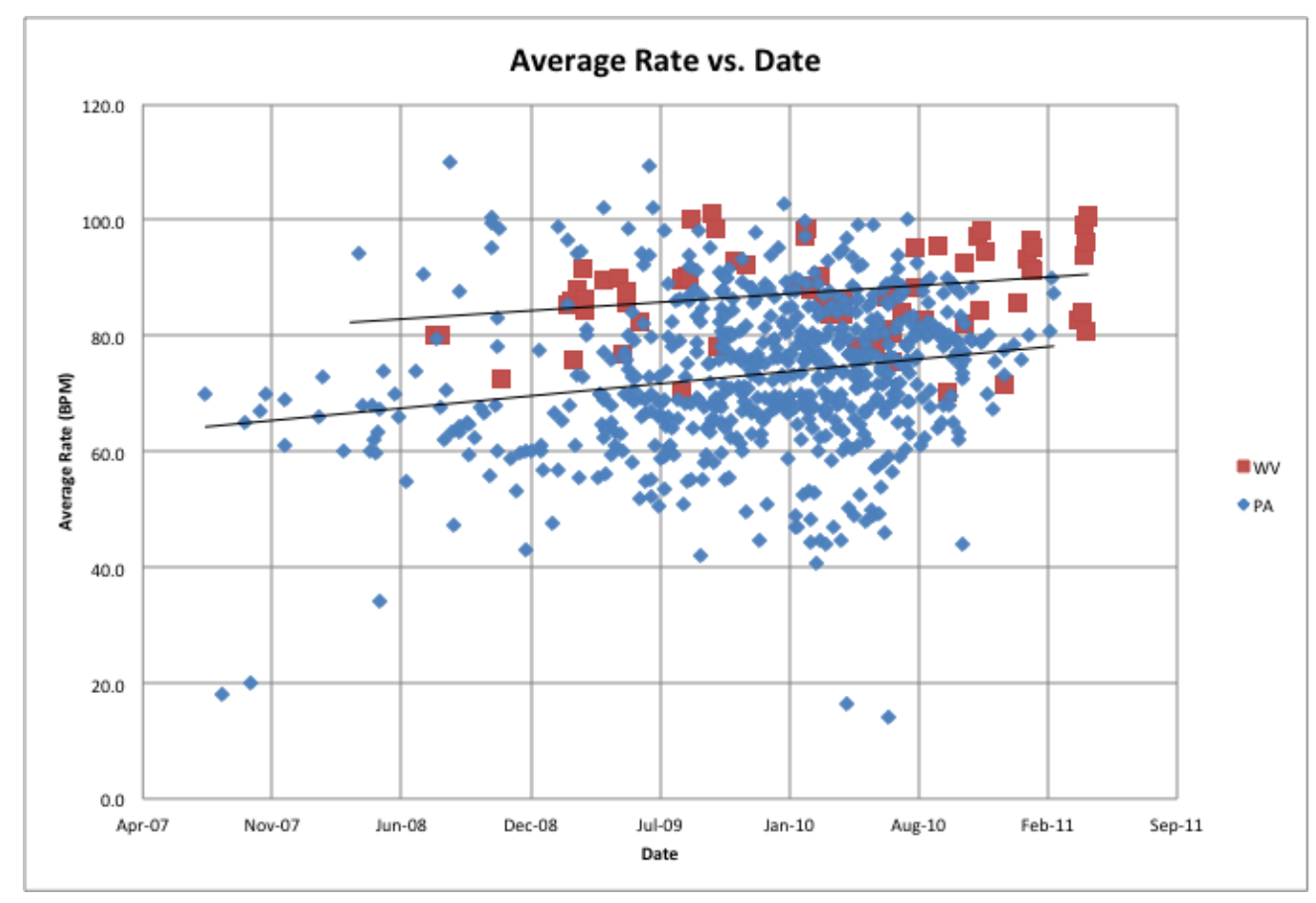

Figure A3 
Figure A4 and A5 below show the locations of the 26 six study wells chosen that are located in Lycoming County and Susquehanna County, Pennsylvania. These wells are all located geographically close to one another. This was in an effort to eliminate any additional variations in well performance that could be due to geological differences.

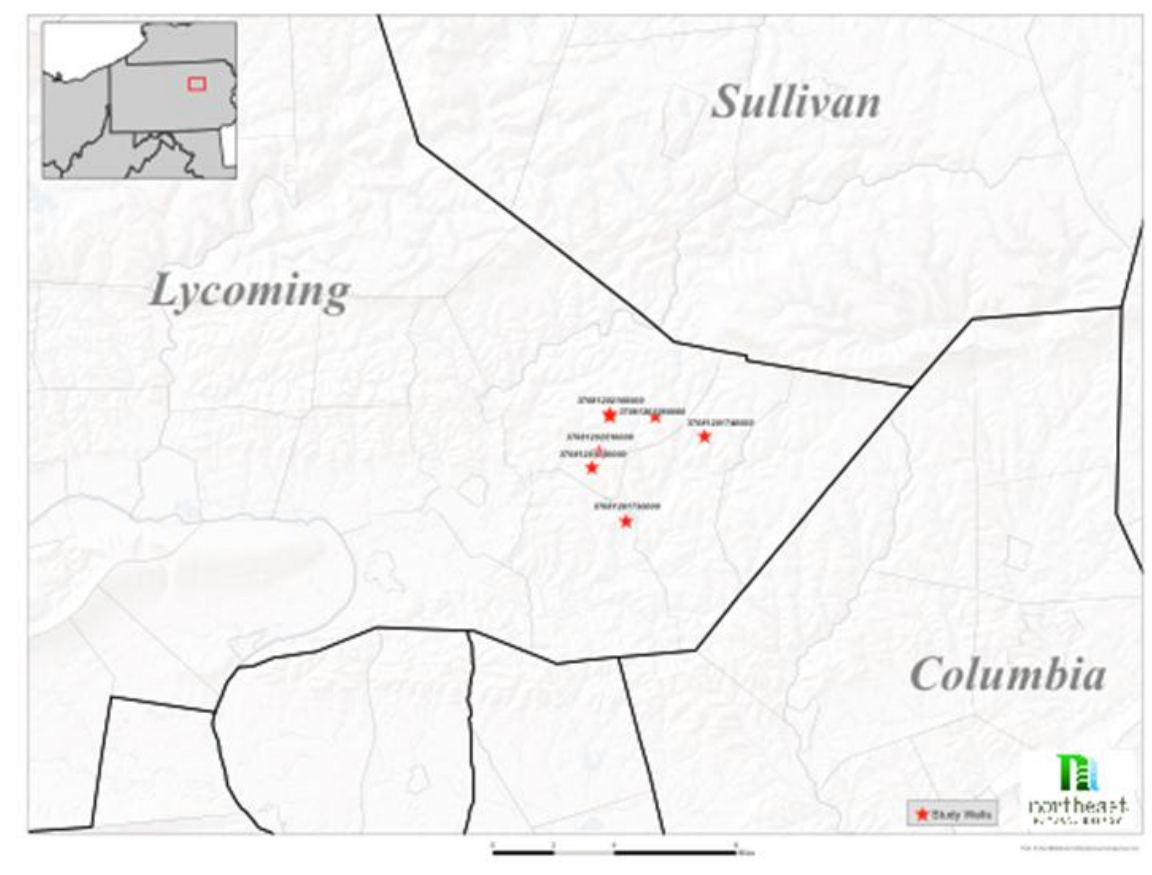

Figure A4. (Courtesy of NNE)

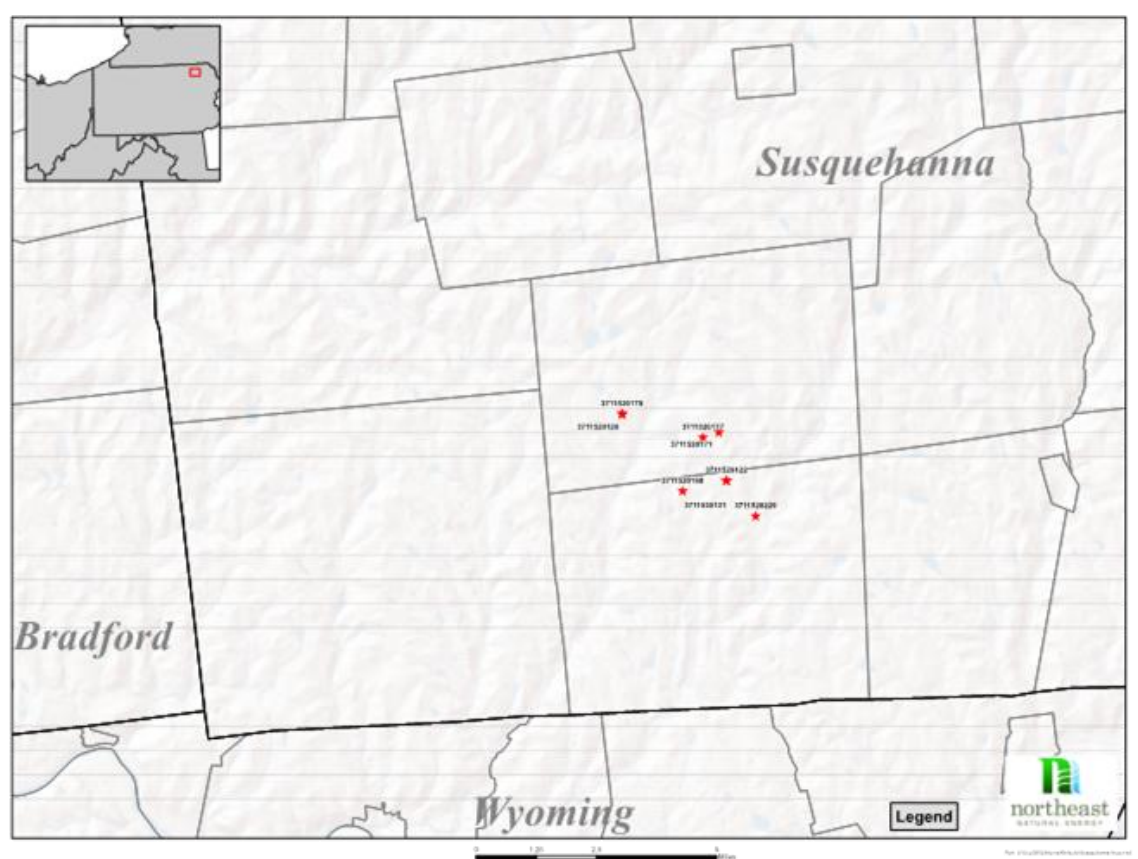

Figure A5. (Courtesy of NNE). 
Similar to Figure 4.6 above, Figure A6 illustrates the thickness of the Marcellus Shale in Pennsylvania. This particular map was used to determine the formation thickness in Lycoming and Susquehanna counties.

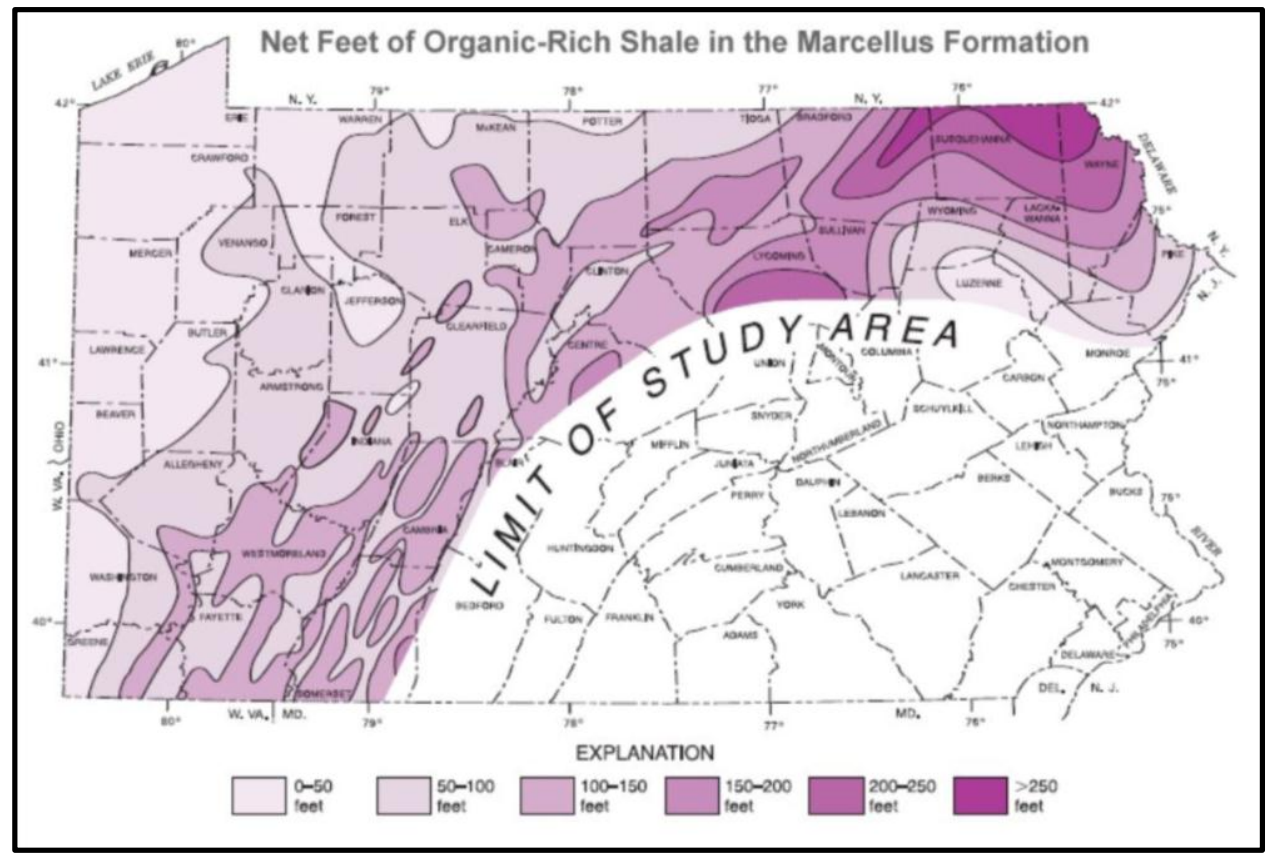

Figure A6. ("Net feet of," 2010).

Figure A7 and A8 represent the daily flowrate and cumulative production history matching curves generated for Study Well W3. These are significant because this particular well experienced a shut in period. These figures illustrate that the model can easily adjust for different situations in the lifetime of a well.

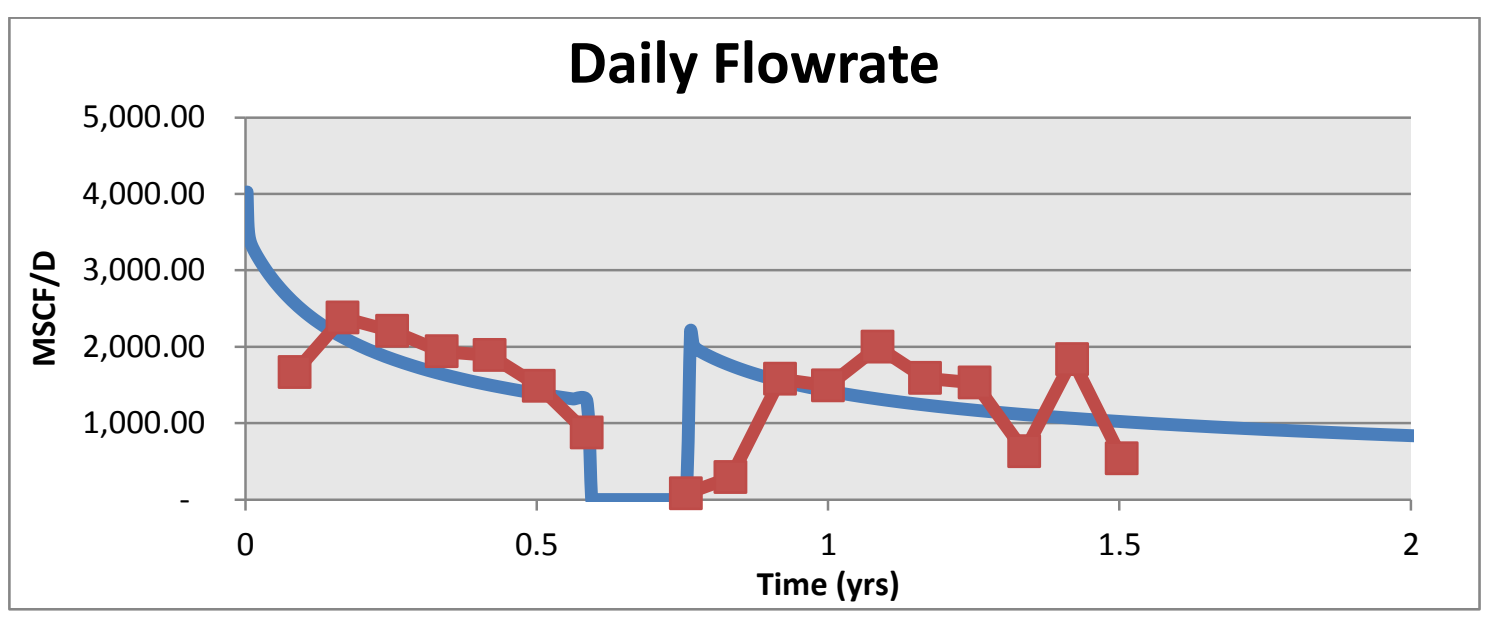

Figure A7 


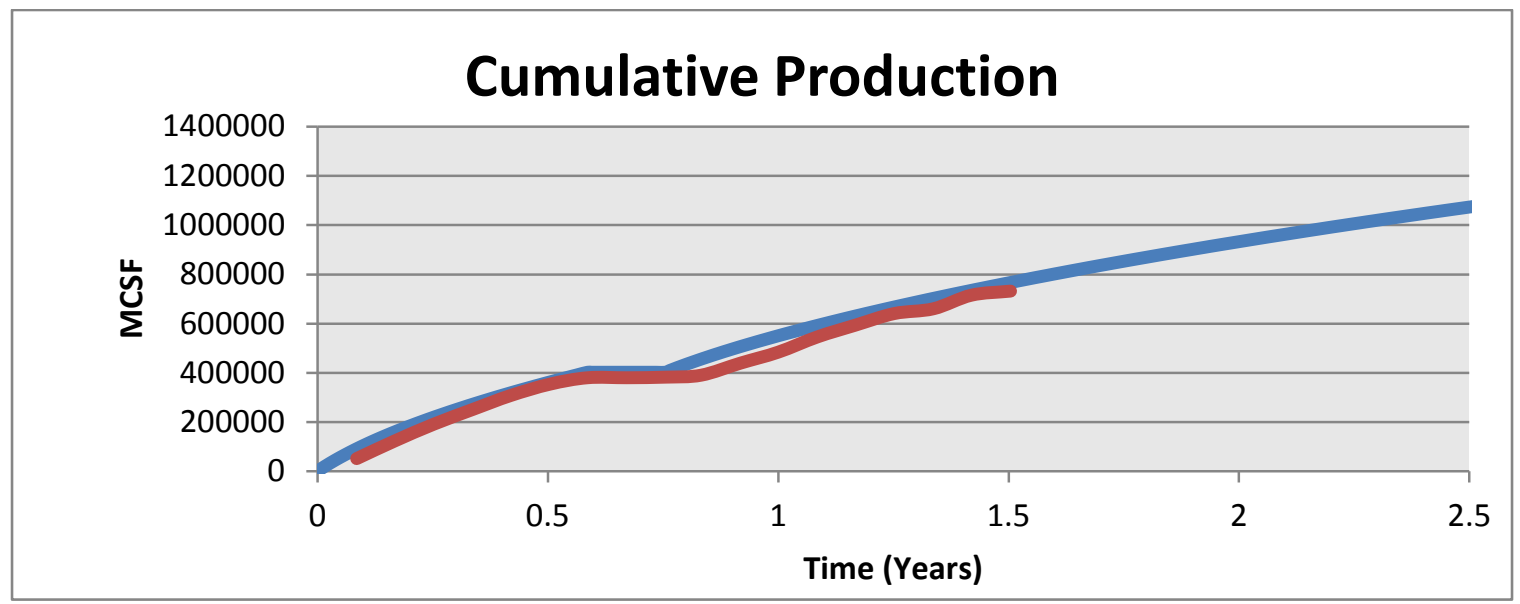

Figure A8

Figure A9 illustrates the trend discussed earlier that is observable between the 10 year predicted production performance and the volume of water per stage used during stimulation. This trend appears to become stronger with time. Figure A9 shows just the data from Susquehanna County, Pennsylvania.

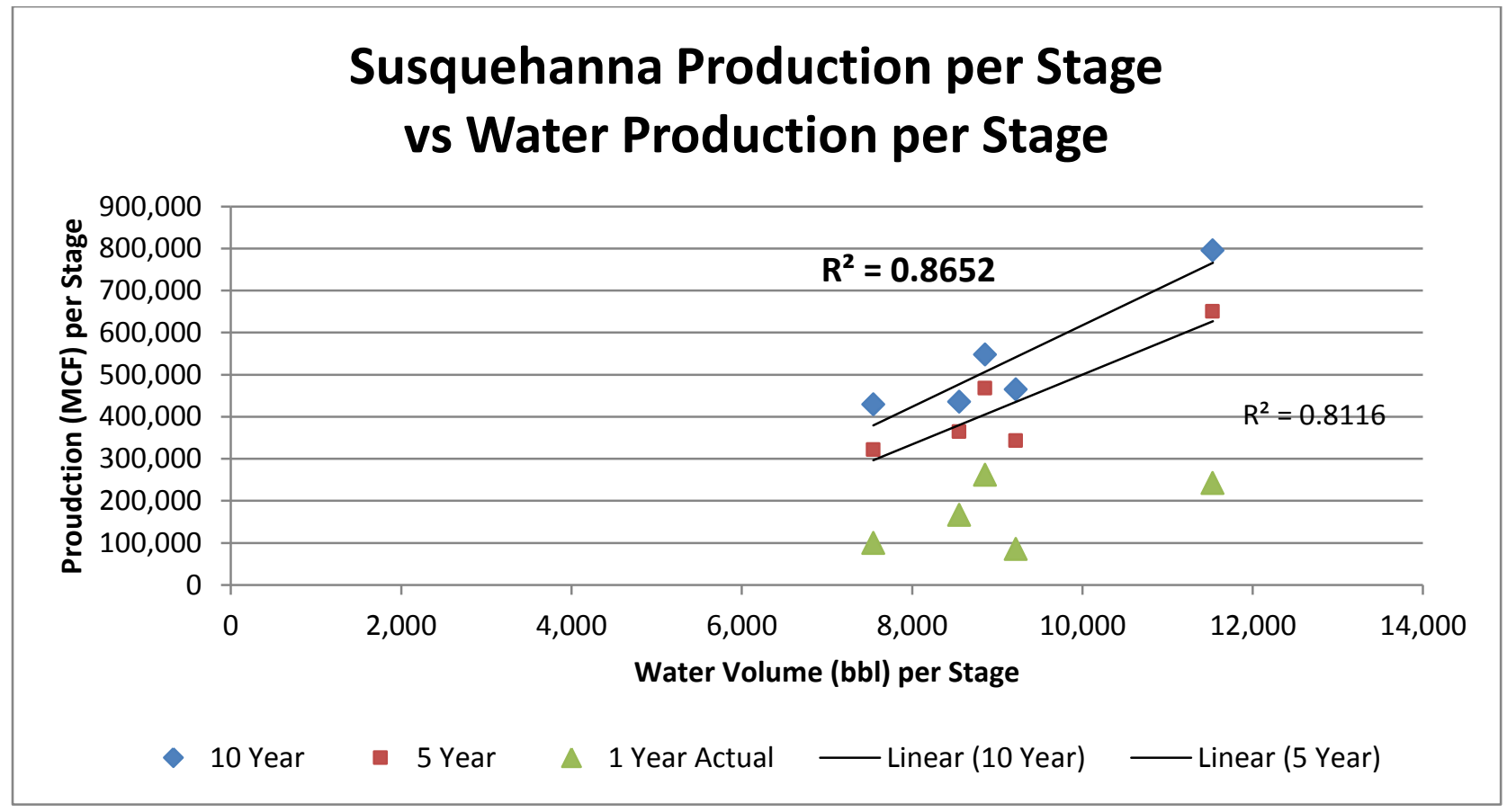

Figure A9 
Both Figure A10 and A11 represent data combined from the 10 year predicted production analysis from Greene and Lycoming counties, Pennsylvania. These are included to show that the 10 year predicted production curve has a very good correlation value for both the water volume per stage and the sand volume per stage.

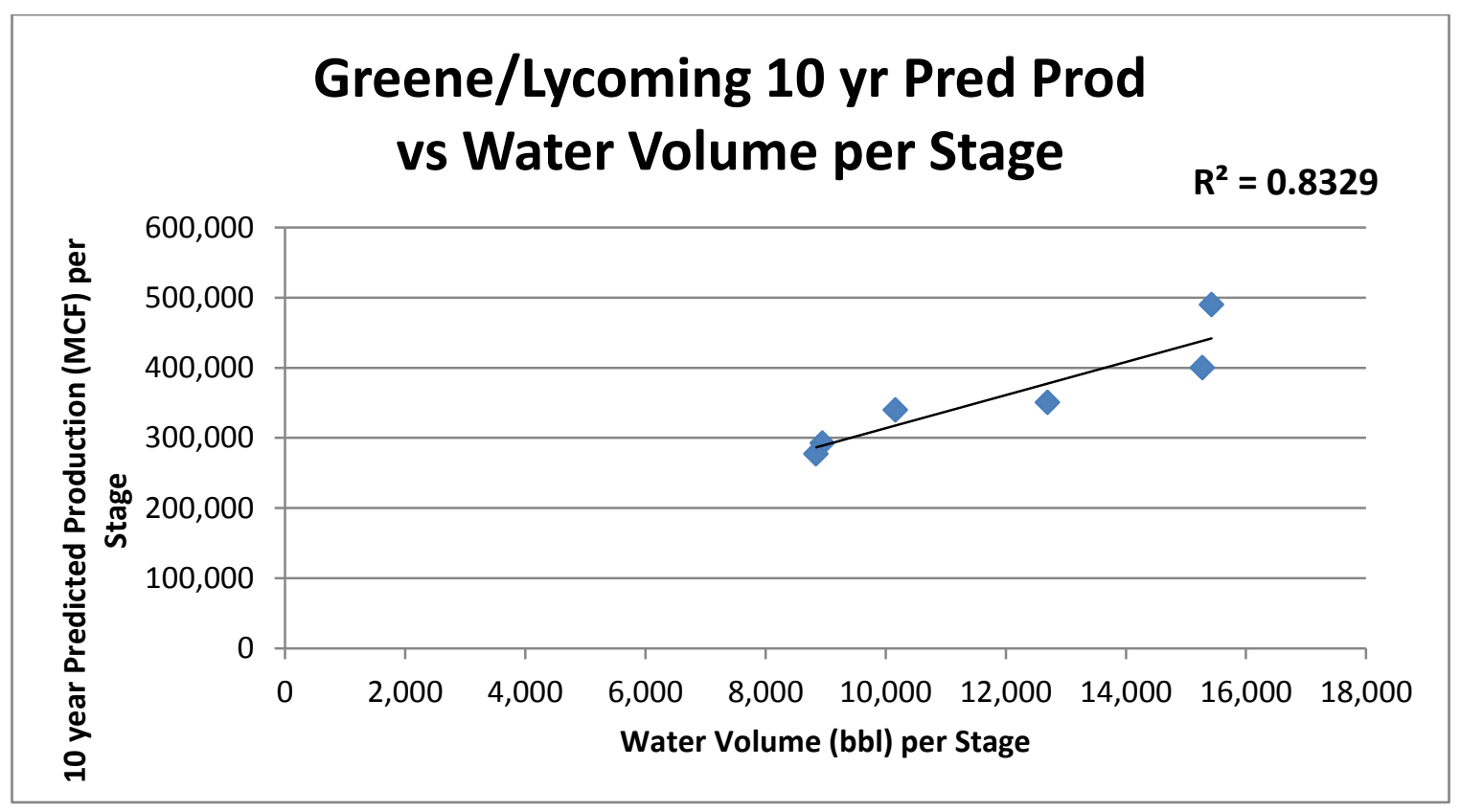

Figure A10

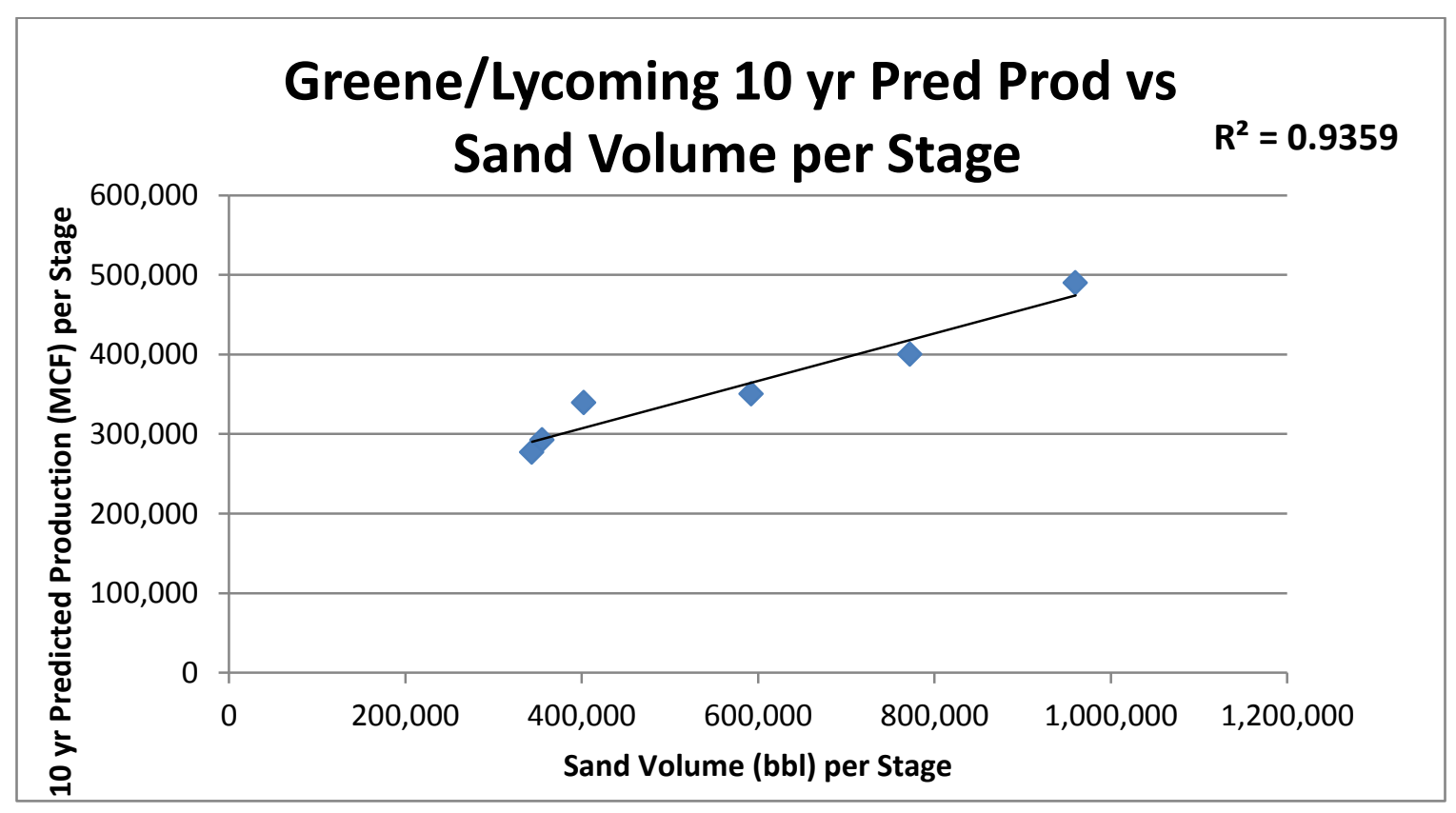

Figure A11 


\section{Appendix B}

\section{Study Well G1}
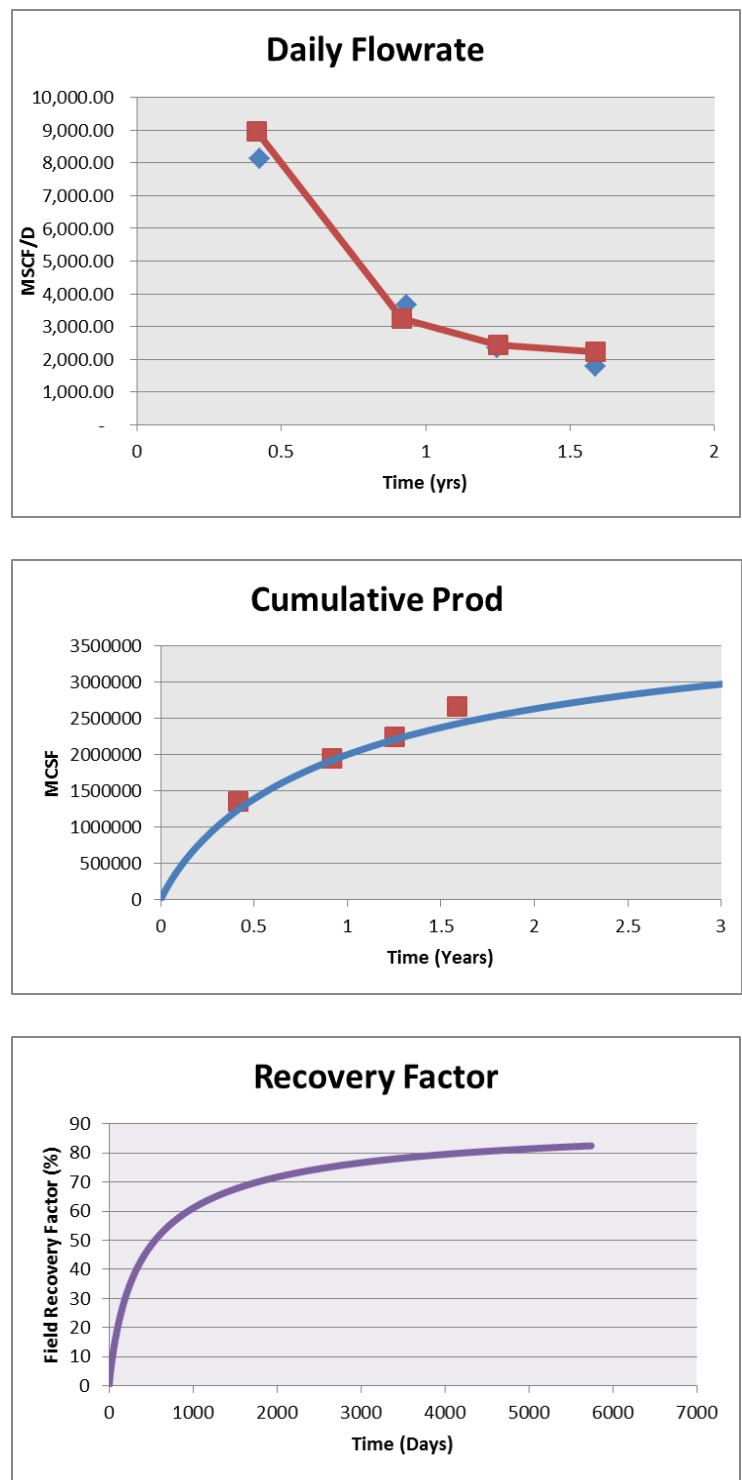

Study Well G2
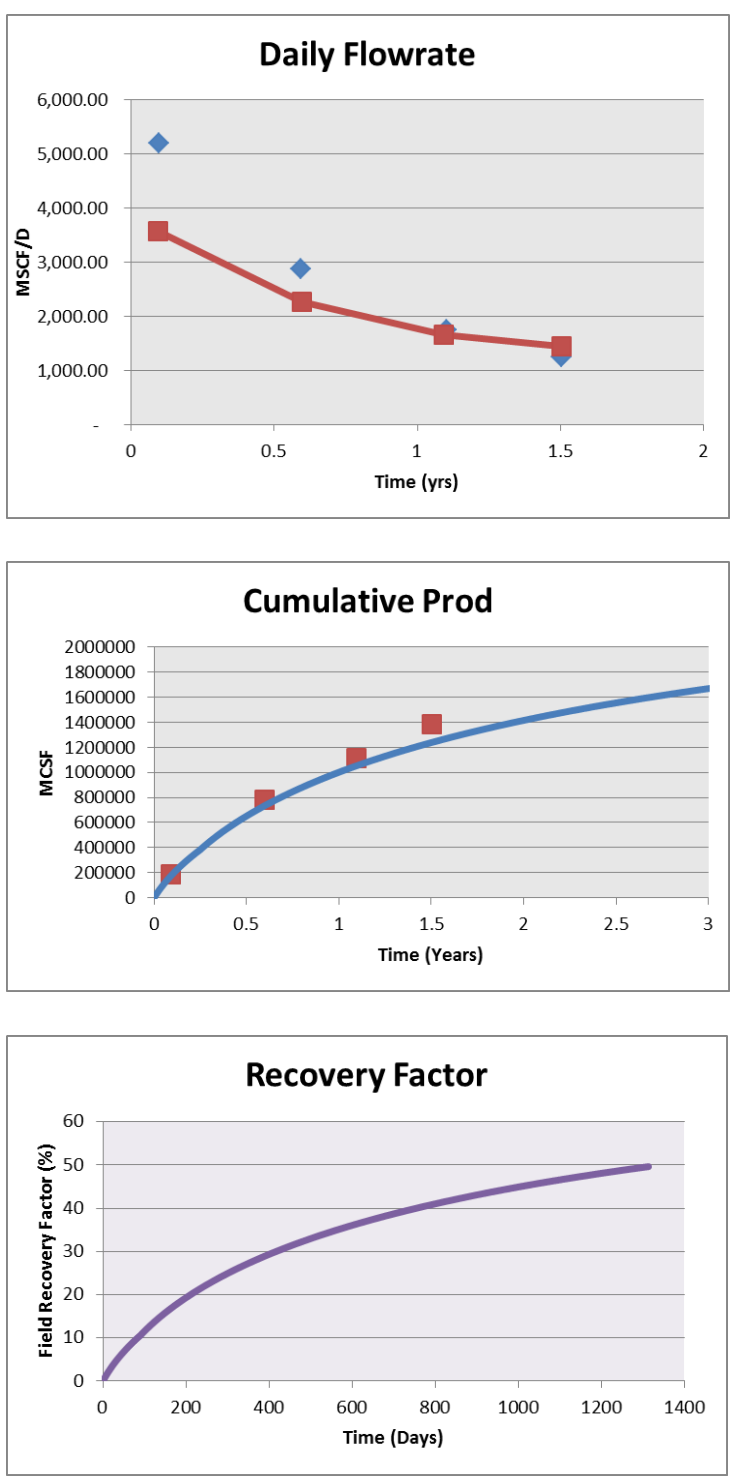
Study Well G3
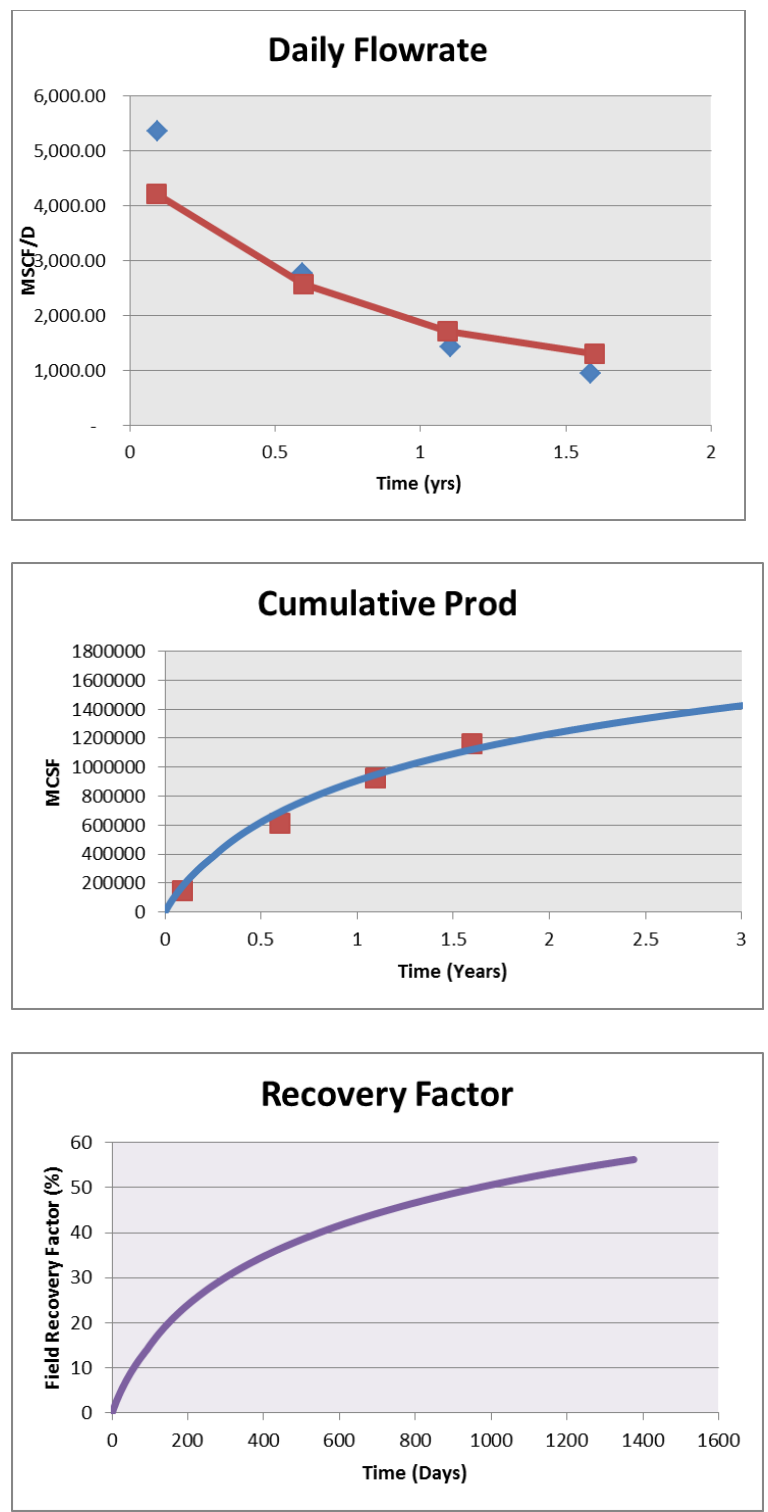

Study Well L1
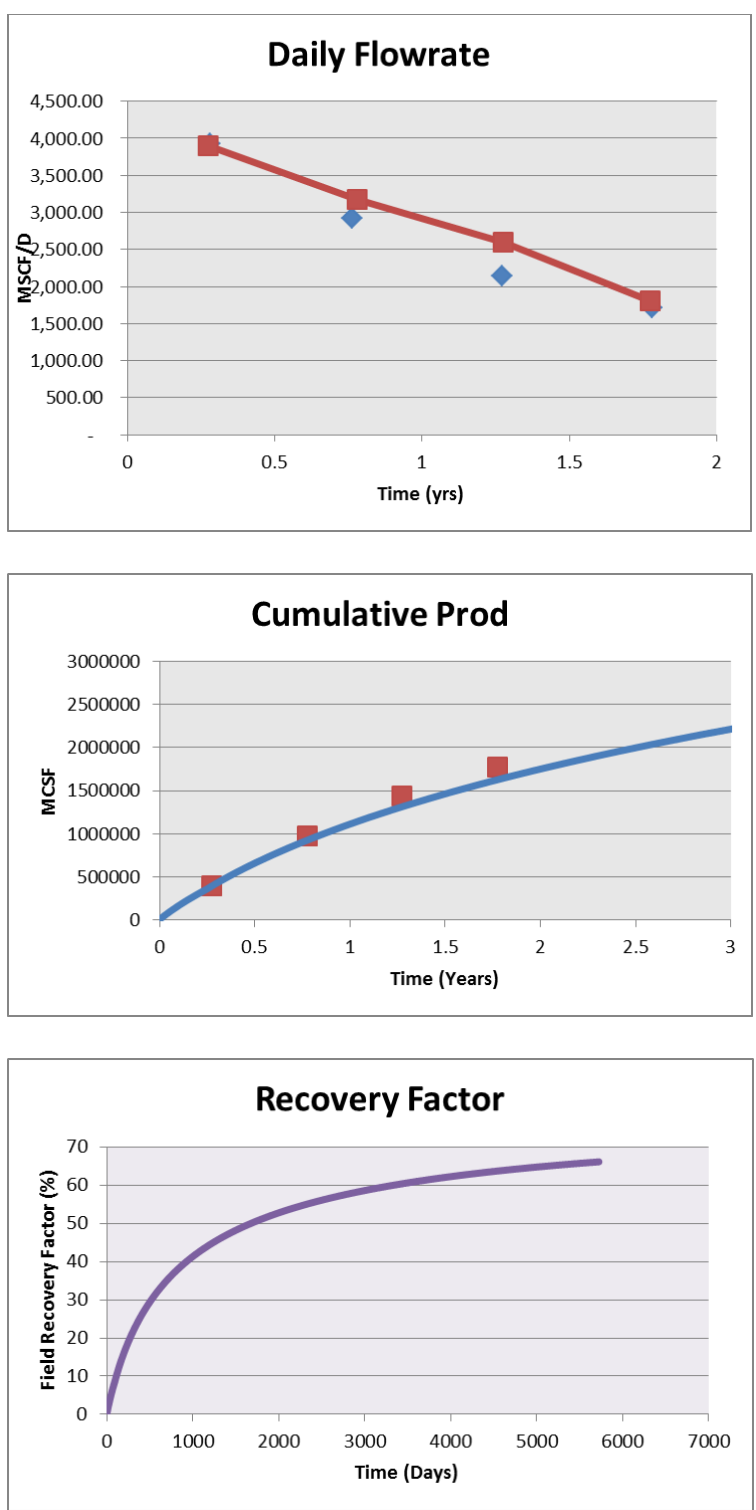
Study Well L2
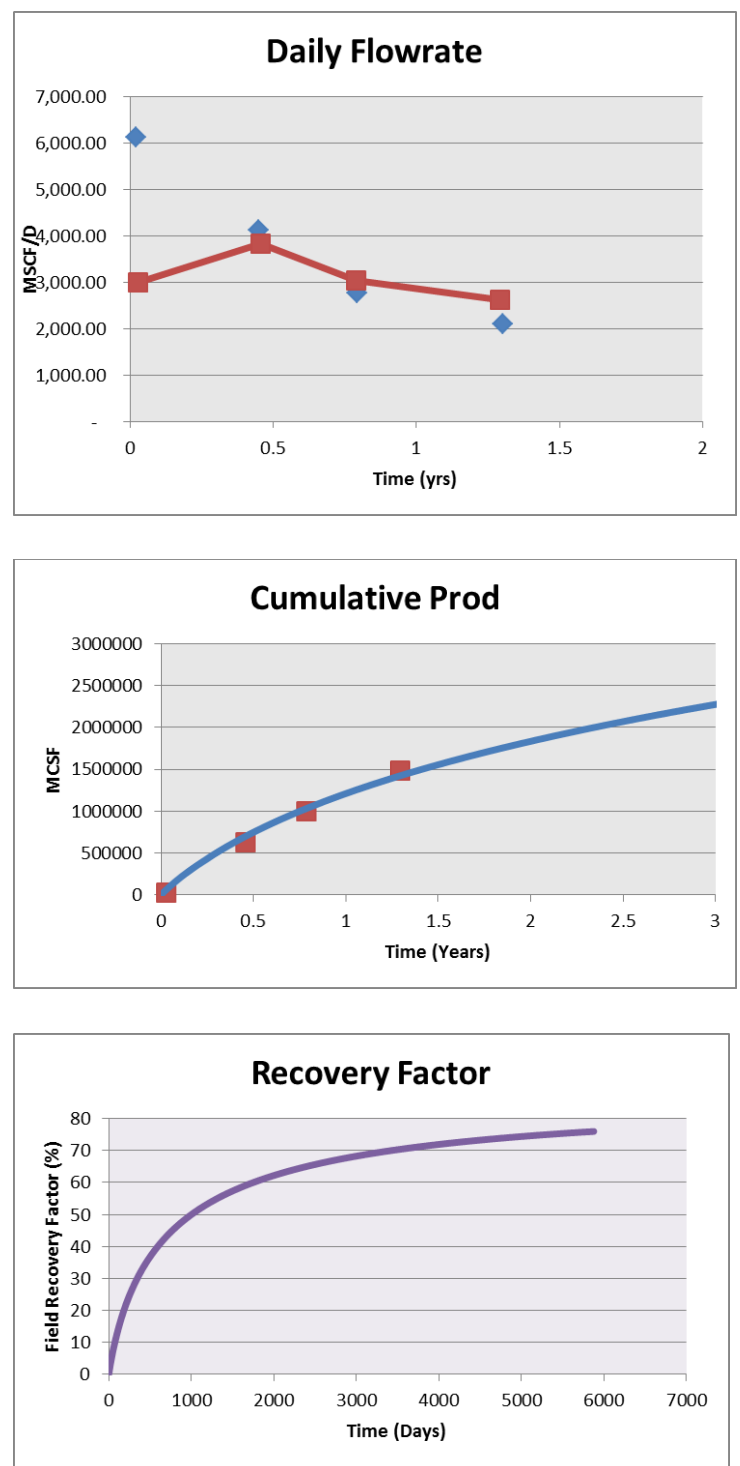

\section{Study Well L3}
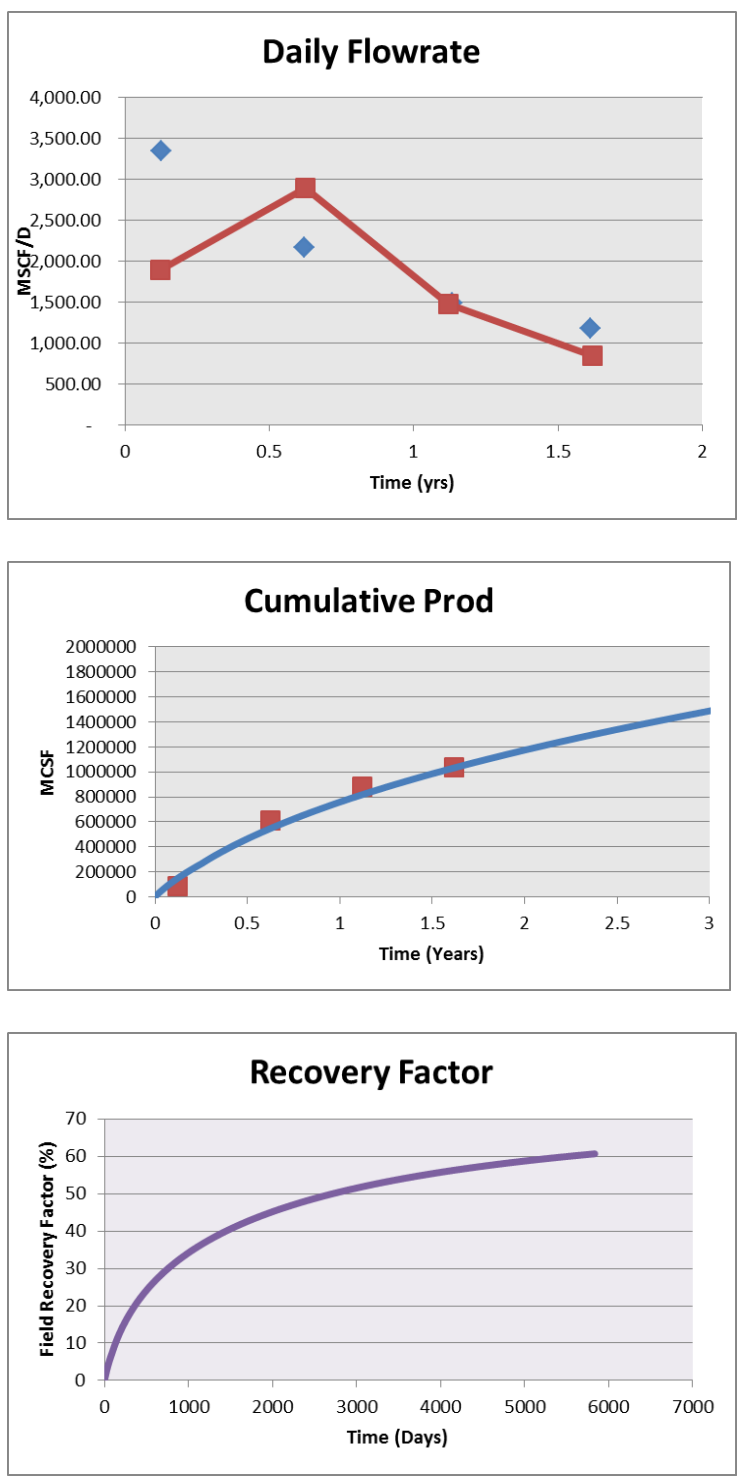


\section{Study Well S1}
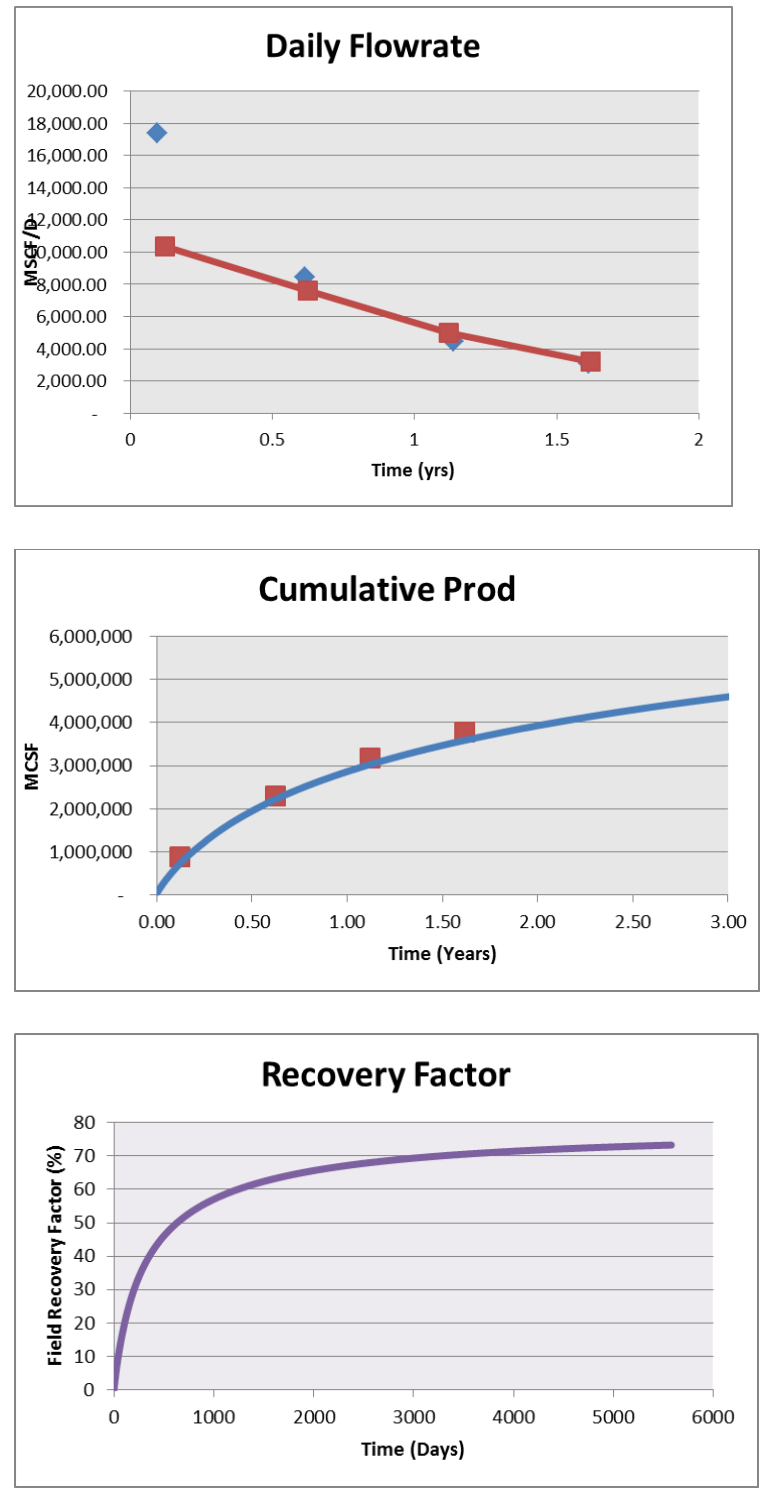

Study Well S2
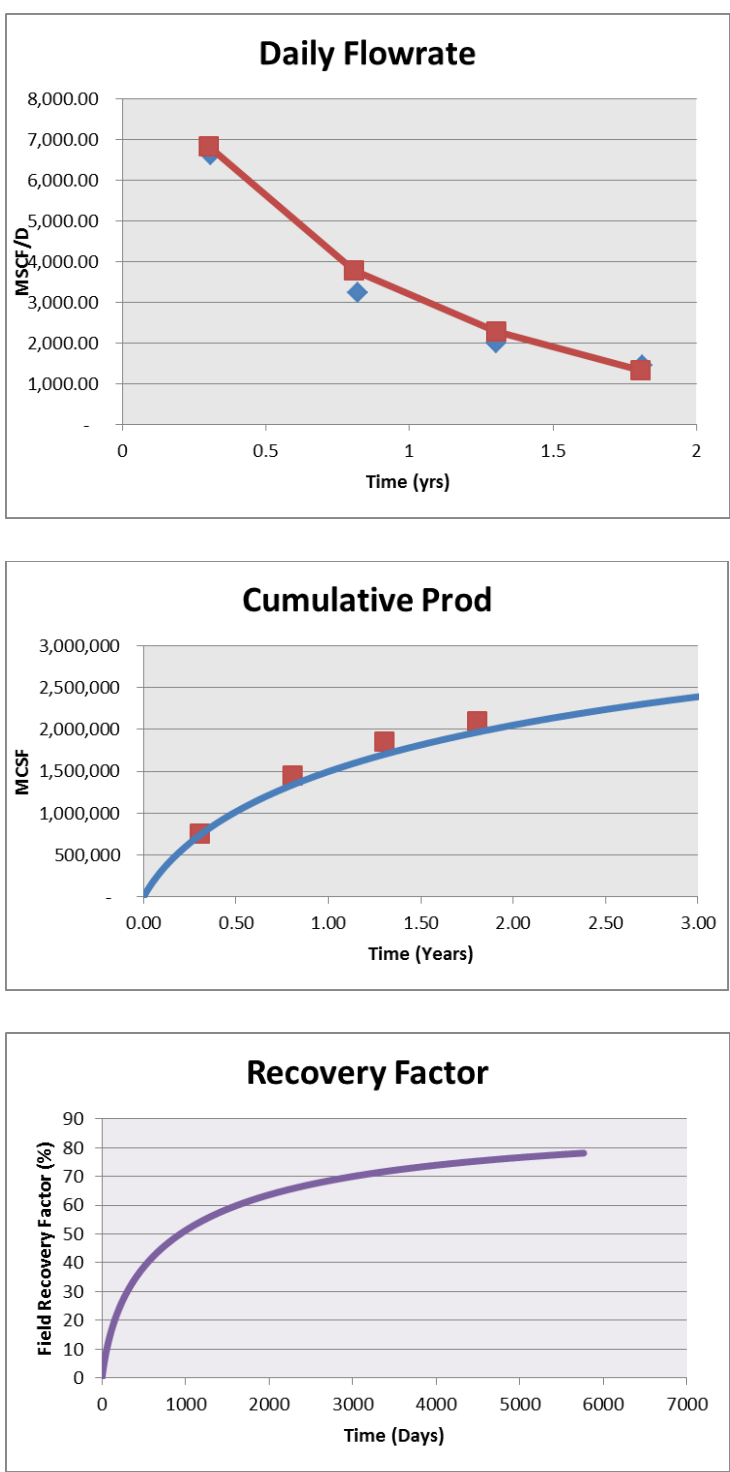


\section{Study Well S3}
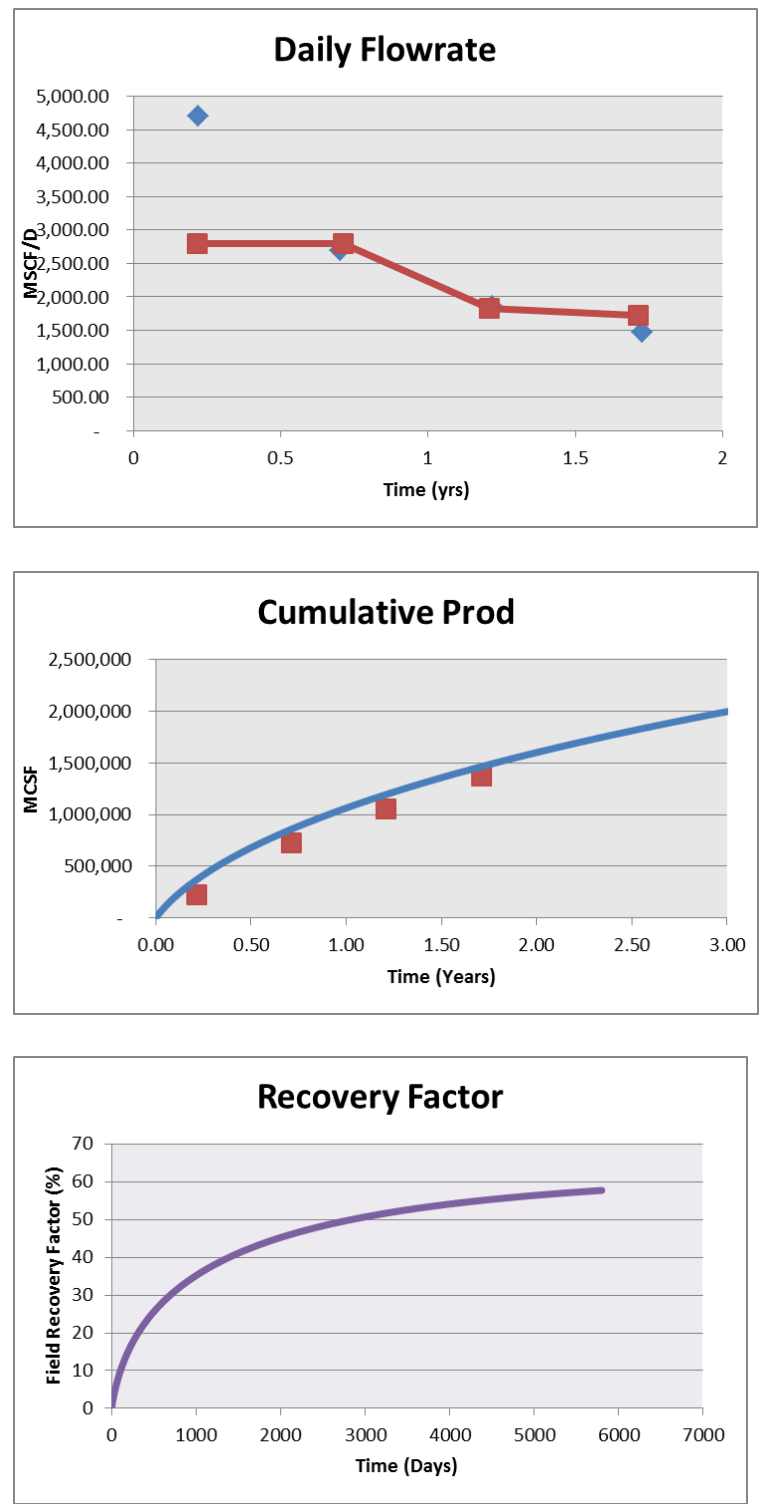

Study Well S4
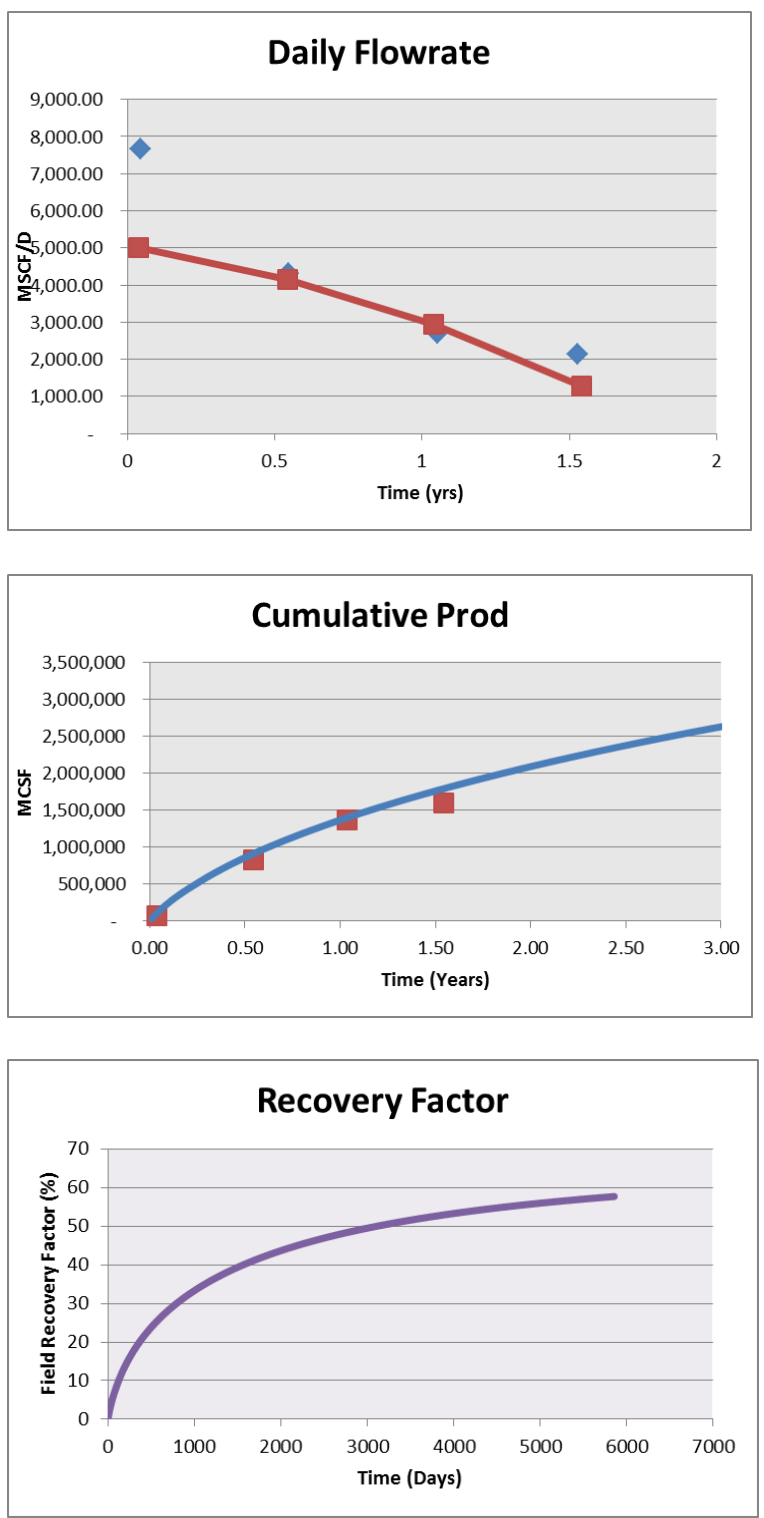
Study Well S5
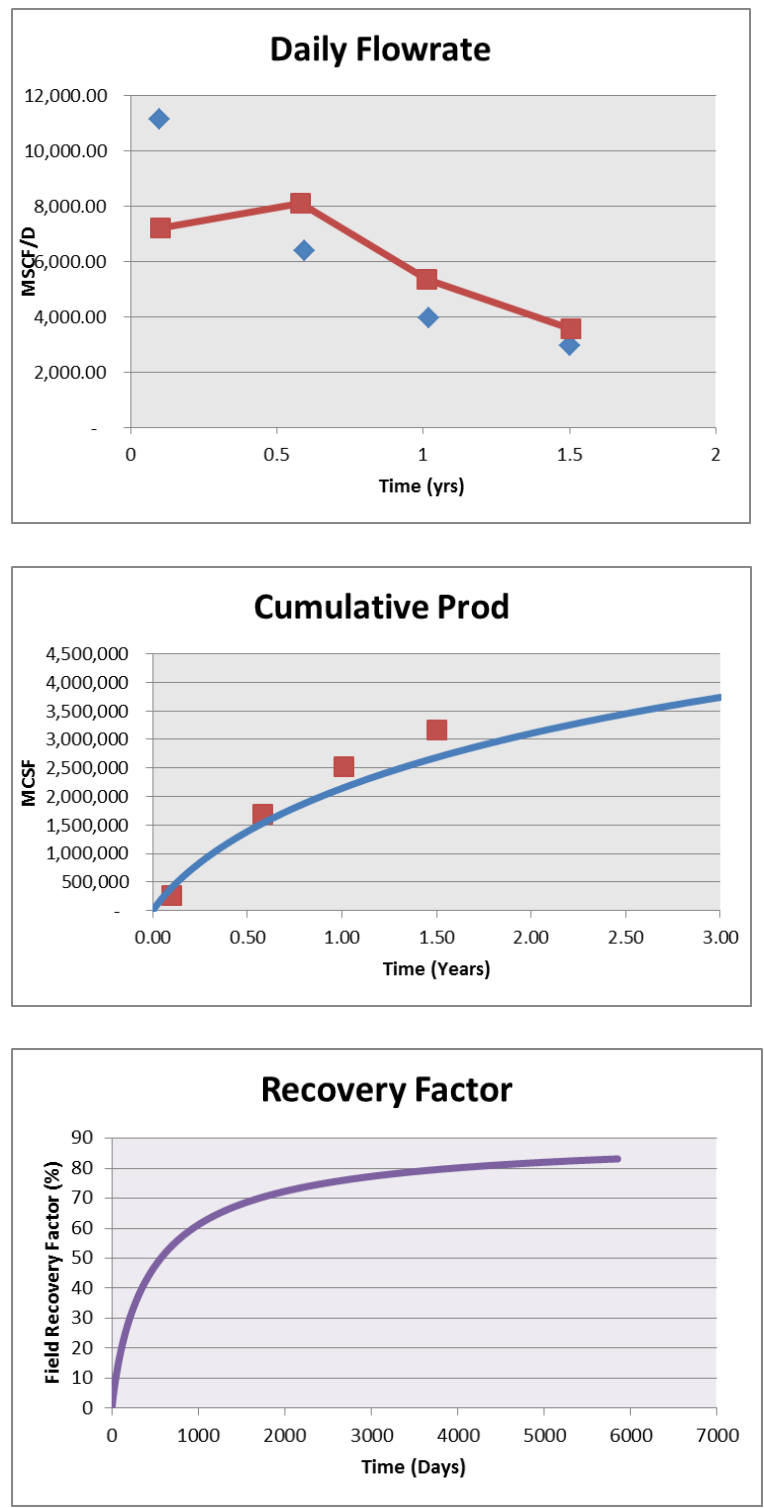

Study Well W1
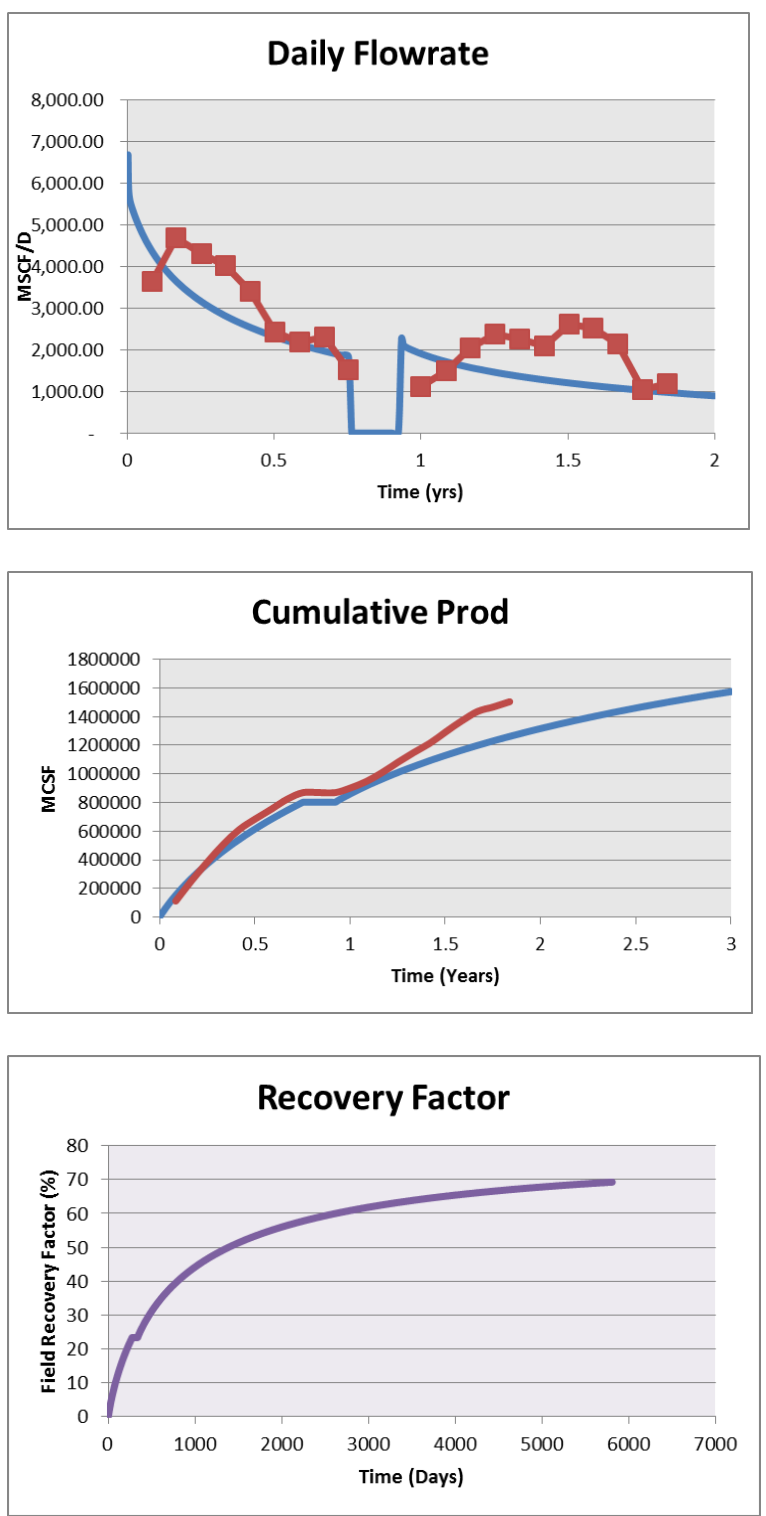
Study Well W2
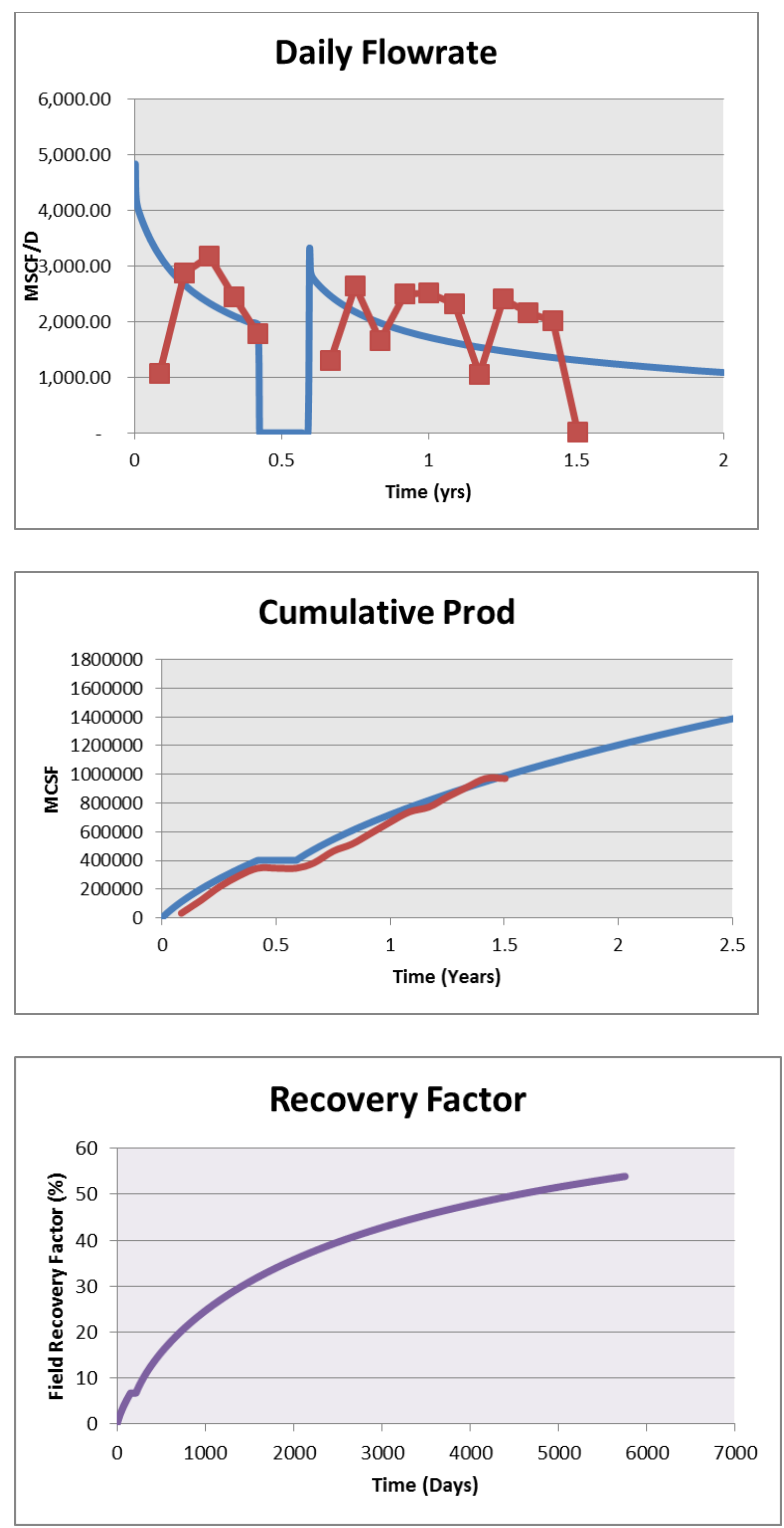

\section{Study Well W3}
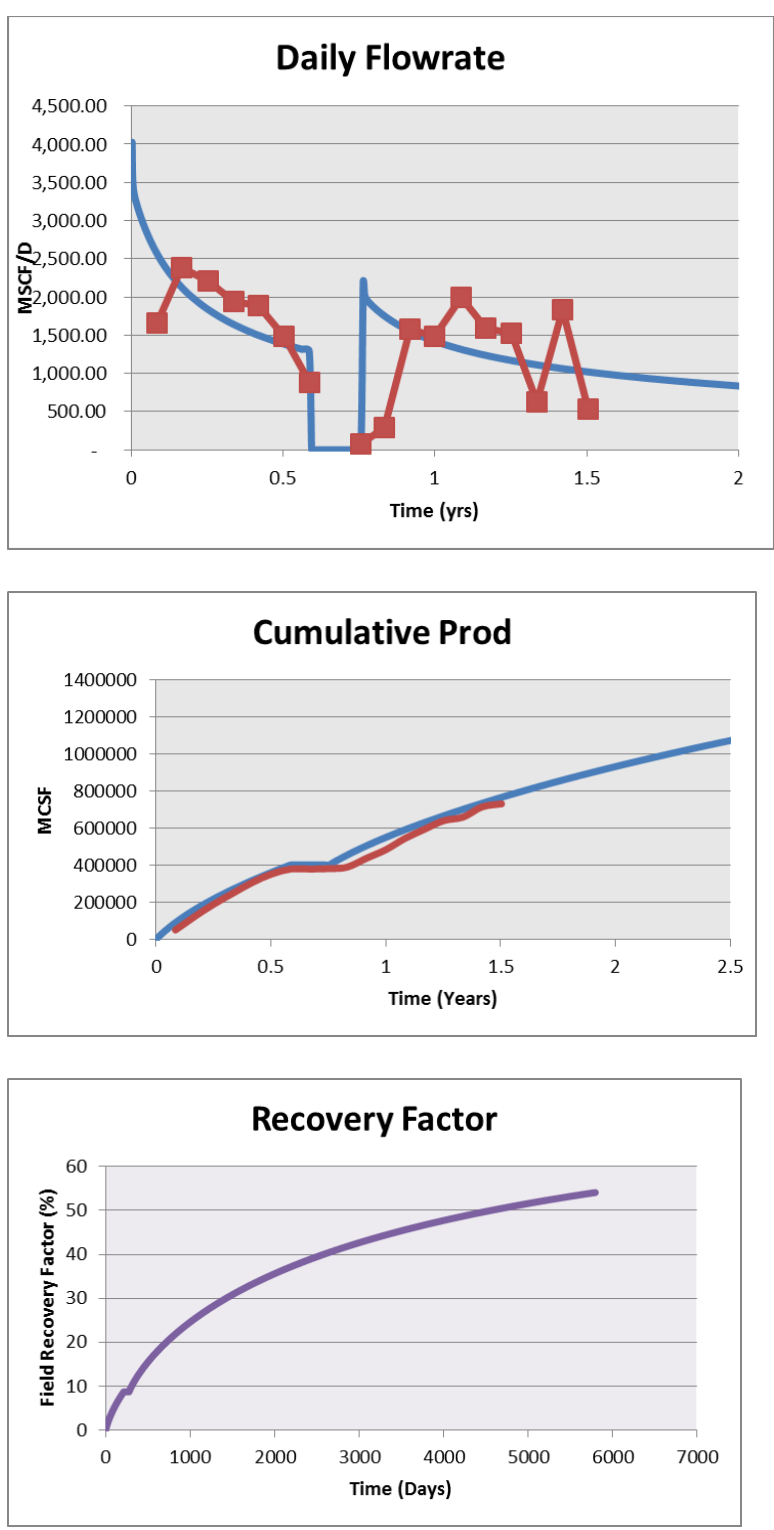


\section{Curriculum Vitae}

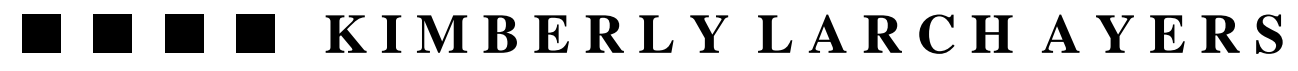

\begin{tabular}{|c|c|c|}
\hline \multirow{4}{*}{ EDUCATION } & 102 EAGLE DRIVE & $\begin{array}{r}\text { MAIDSVILLE, WV } 26541 \begin{array}{r}\text { CELL: 304.839.4089 } \\
\text { LARCHKL@ GMAIL.COM }\end{array}\end{array}$ \\
\hline & MASTERS OF SCIENCE DEGREE & $\begin{array}{l}\text { WEST VIRGINIA UNIVERSITY GPA: } 3.89 / 4.0 \\
\text { Petroleum \& Natural Gas Engineering } \\
\text { EXPECTED GRADUATION MAY } 2012\end{array}$ \\
\hline & $\begin{array}{l}\text { BACHELOR OF SCIENCE DEGREE } \\
\text { MAGNA CUM LAUDE }\end{array}$ & $\begin{array}{l}\text { WEST VIRGINIA WESLEYAN COLLEGE May } 2010 \\
\text { Mathematics } \\
\text { GPA: } 3.81 / 4.0\end{array}$ \\
\hline & $\begin{array}{l}\text { BACHELOR OF ARTS DEGREE } \\
\text { MAGNA CUM LAUDE }\end{array}$ & $\begin{array}{l}\text { WEST VIRGINIA WESLEYAN COLLEGE May } 2010 \\
\text { Chemistry } \\
\text { MINORS: Honors, Music-Piano } 3.81 / 4.0\end{array}$ \\
\hline
\end{tabular}

\section{WORK EXPERIENCE}

NORTHEAST NATURAL ENERGY, LLC

Engineering Intern
CHARleston \& MORgantown, WV Summer 2011-Spring 2012

- Worked closely with drilling and completion operations of Marcellus Shale wells

- Helped in developing AFEs and bidding work for Marcellus Shale drilling

program

- Completed ARIES evaluations of shallow field operations

- Assisted in production operations of shallow Pennsylvania wells

- Regularly updated and tracked invoicing, costs, and well production

LARCH OIL \& GAS CORPORATION

Development, Royal Distribution, \& Permitting

CHARLESTON, WV 2006-2011

- Assisted in developing historical production in the Kanawha County area

- Small, family owned and operated company allowed for multi-faceted experience

- Managed all land, permitting, and royalty distribution activities

- Tracked all well production and suggested improvements and new projects

- Developed small, investor-based drilling program

TIMBERLINE JUNIOR SKI RACE TEAM

Coach and Official

DAVIS, WV 2006-2011

- Officiated and organized regional and local events

- Instructed children from ages five to eighteen in the technical aspects of ski racing

- Improved personal communication skills with both athletes and parents

- Developed leadership abilities and learned to work as a team with other coaches

WVWC DEPARTMENT OF CHEMISTY

Chemical Hygene \& Administrative Assistant

BUCKHANNON, WV 2007-2008

- Developed knowledge of administrative management practices and problem solving techniques

- Assisted in the development of a Chemical Hygiene Plan

- Learned the importance of chemical safety in both the labratory and environment 


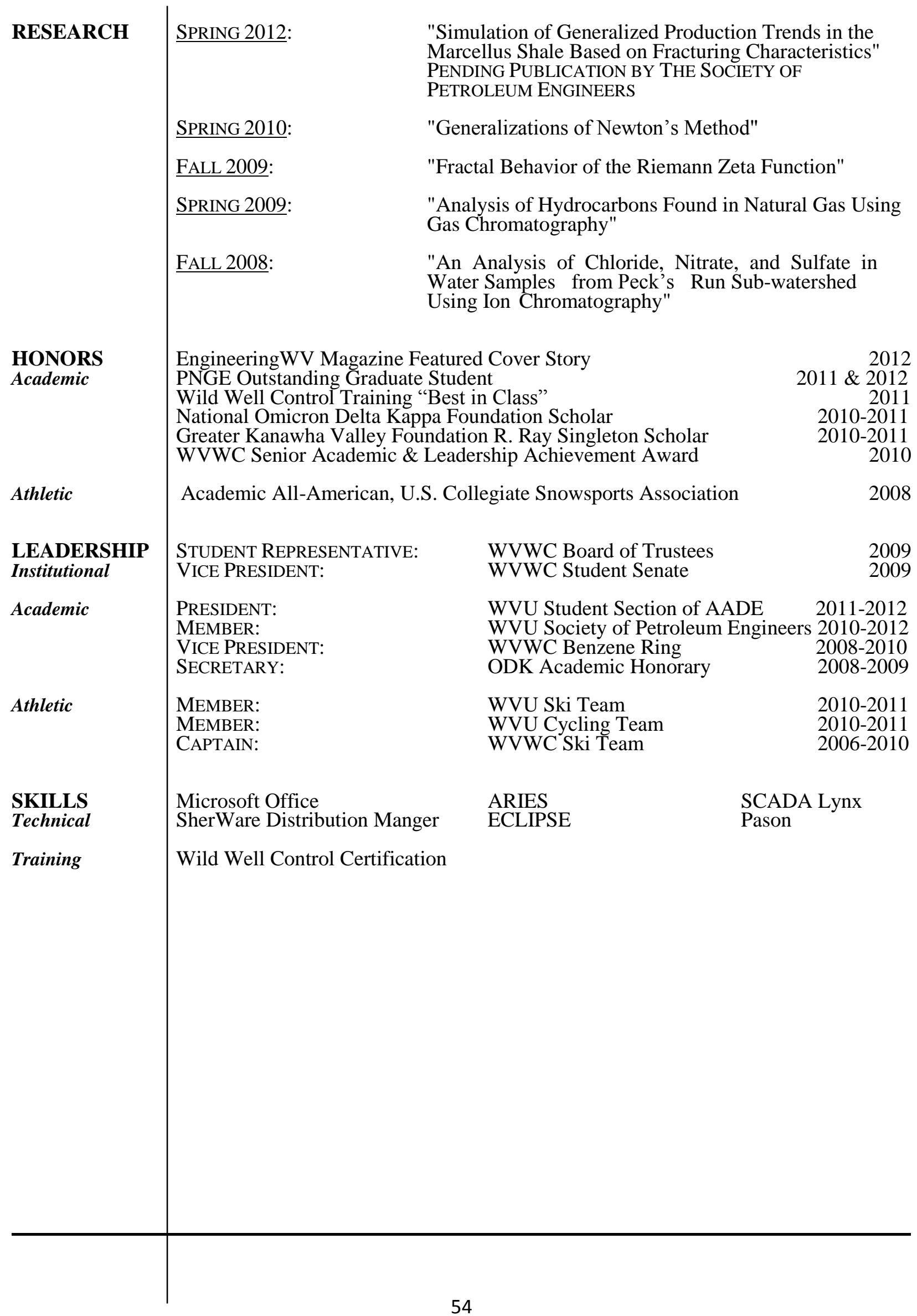

